\title{
Development and therapeutic potential of 2-aminothiazole derivatives in anticancer drug discovery
}

\author{
Seyedeh Roya Alizadeh ${ }^{1}$ Seyedeh Mahdieh Hashemi $\mathbb{C}^{2}$
}

Received: 23 September 2020 / Accepted: 6 December 2020 / Published online: 15 January 2021

(c) The Author(s), under exclusive licence to Springer Science+Business Media, LLC part of Springer Nature 2021

\begin{abstract}
Currently, the development of anticancer drug resistance is significantly restricted the clinical efficacy of the most commonly prescribed anticancer drug. Malignant disease is widely prevalent and considered to be the major challenges of this century, which concerns the medical community all over the world. Consequently, investigating small molecule antitumor agents, which could decrease drug resistance and reduce unpleasant side effect is more desirable. 2-aminothiazole scaffold has emerged as a promising scaffold in medicinal chemistry and drug discovery research. This nucleus is a fundamental part of some clinically applied anticancer drugs such as dasatinib and alpelisib. Literature survey documented that different 2aminothiazole analogs exhibited their potent and selective nanomolar inhibitory activity against a wide range of human cancerous cell lines such as breast, leukemia, lung, colon, CNS, melanoma, ovarian, renal, and prostate. In this paper, we have reviewed the progresses and structural modification of 2-aminothiazole to pursuit potent anticancers and also highlighted in vitro activities and in silico studies. The information will useful for future innovation.
\end{abstract}

Seyedeh Mahdieh Hashemi

hashemi325@gmail.com

1 Student Research Committee, Department of Medicinal

Chemistry, Faculty of Pharmacy, Mazandaran University of

Medical Sciences, Sari, Iran

2 Department of Medicinal Chemistry and Pharmaceutical Sciences Research Center, Faculty of Pharmacy, Mazandaran University of Medical Sciences, Sari, Iran 


\section{Graphical Abstract}

Representatives of 2-aminothiazole-containing compounds classification

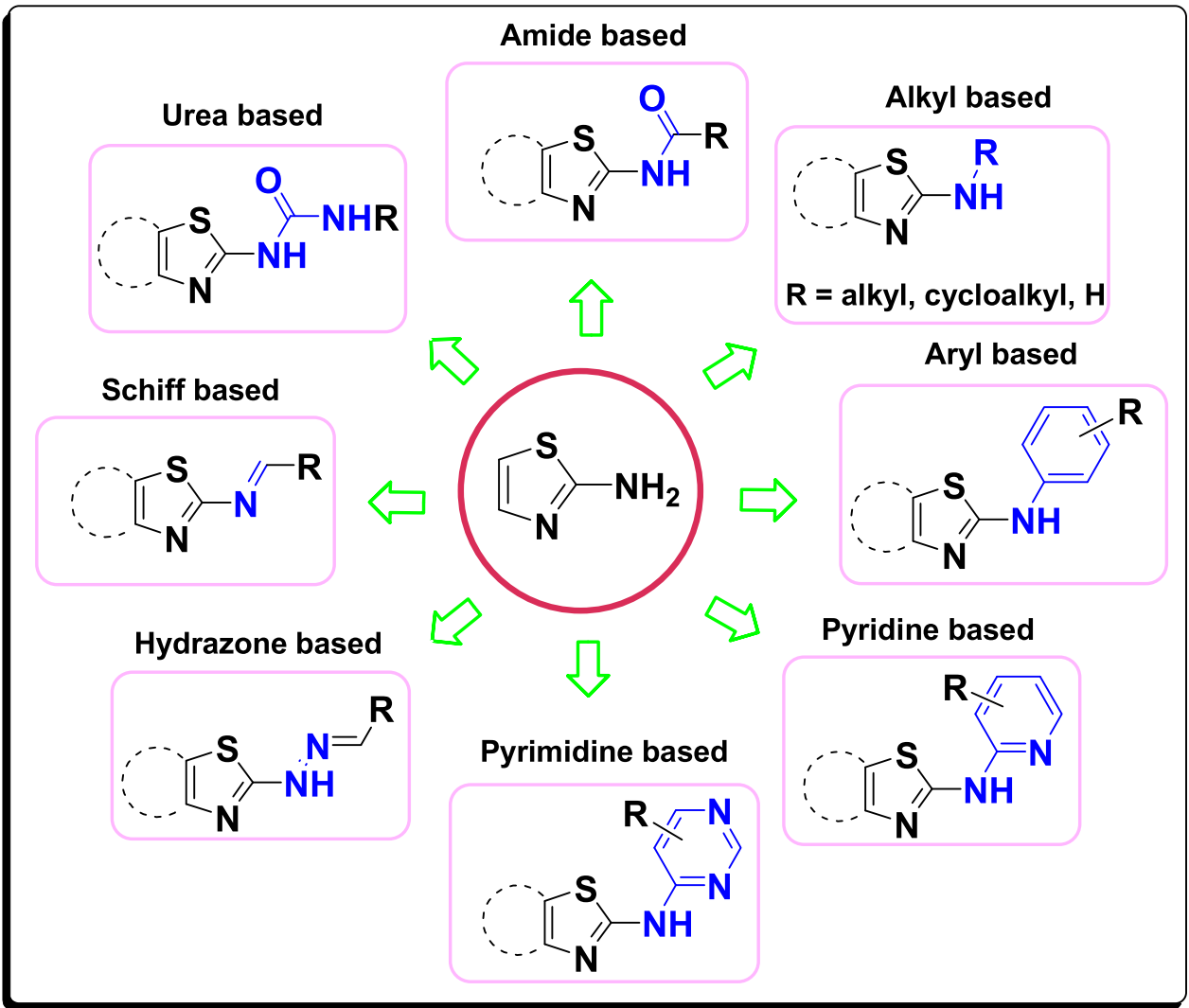

Keywords 2 -aminothiazole $\cdot$ Anticancer $\cdot$ SAR study $\cdot$ Hantzsch's synthesis $\cdot$ Dasatinib $\cdot$ Alpelisib

\section{Introduction}

Malignant disease is widely prevalent and considered to be the major challenges of this century, which concerns the medical community all over the world [1]. Cancer has sustained cellular proliferative capacity. Although the mechanism of initiation and progression of cancer has been well established, the successful treatment of cancer remains a huge challenge facing the lack of early detection, undefined tumor cell dormancy status, and metastatic properties of malignant tumor [2,3]. The development of anticancer drug resistance, which leads to the failure of most chemotherapeutic anticancer treatments, is significantly restricted the clinical efficacy of the most commonly prescribed anticancer drug [4]. Consequently, there is an urgent need for the implementation of efficient prevention and treatment strategies to curb cancer deaths. Investigating small molecule antitumor agents, which could decrease drug resistance and reduce unpleasant side effect is more desirable [5].

2-aminothiazole scaffold has emerged as a promising scaffold in medicinal chemistry and drug discovery research considering its broad pharmacological spectrum [6]. Literature survey documented that 2-aminothiazole derivatives represent a class of heterocyclic ring system that possess antiviral [7], antimicrobial [8], anticancer [9], anticonvulsant [10], antidiabetic [11], antihypertensive [12], antileishmanial [13], and anti-inflammatory activities [14]. Also, in vitro anticancer evaluation studies of different 2-aminothiazole analogs exhibited their potent and selective nanomolar inhibitory activity against a wide range of human cancerous cell lines such as breast, leukemia, lung, colon, CNS, melanoma, ovarian, renal, and prostate [15-17].

Recently, extensive efforts have been made to enhance the antitumor activities of the 2-AT (2-AminoThiazole) core in anticancer therapeutic areas, as exemplified by Fig. 1. Alpelisib (1), which is an oral $\alpha$-specific PI3K inhibitor, was recently approved for the treatment of metastatic or otherwise advanced breast cancer [18]. SNS-032 (2) is a potent, selective inhibitor of cyclin-dependent kinases [19]. KY05009 (3) showed low nanomolar antitumor activity and selectivity toward human lung adenocarcinoma A549 cells, which were identified as Traf2- and Nck-interacting kinase 
<smiles>Cc1nc(NC(=O)N2CCCC2C(N)=O)sc1-c1ccnc(C(C)(C)C(F)(F)F)c1</smiles>

1 (Alpelisib)<smiles>Cc1ccc(C(=O)Nc2sc(Nc3ccccc3)nc2C(N)=O)cc1</smiles>

3 (KY-05009)<smiles>Cc1nc(N)sc1-c1ccnc(Nc2ccc(N3CCOCC3)cc2)n1</smiles>

4 (CYC116, Cyclacel)<smiles>Cc1nc(Nc2ncc(C(=O)Nc3c(C)cccc3Cl)s2)cc(N2CCN(CCO)CC2)n1</smiles>

5 (Dasatinib)

Fig. 1 Development of 2-aminothiazole core in anticancer therapeutic areas

inhibitor [20]. CYC116, Cyclacel (4) was an effective Aurora $\mathrm{A} / \mathrm{B}$ inhibitor and a slightly weaker inhibitor of VEGFR2 and was currently in Phase I clinical trials [21]. Dasatinib (5), a novel, highly potent, and multitargeted inhibitor of Abl, Src, and c-Kit kinase, which was potent against unmutated BCR-ABL [22], was recently approved for the oral treatment of CML and Philadelphia chromosome-positive acute lymphoblastic leukemia [23].

Novel 2-aminothiazole anticancer agents owning target specific advanced mechanism of action with favorable therapeutic index are considered valuable in the field of oncology-related drug discovery containing DNA intercalating agents, apoptotic/angiogenesis and cytotoxic agents, inhibitors of multiple enzyme targets such as EGFR/VGFER kinase, Akt (PKB) protein kinase, ALK/TGF- $\beta$ type I receptor kinase, HDAC, B-RAF, Src and Abl kinase, tubulin polymerase, topo isomerase IV, PI $3 \mathrm{~K} / \mathrm{mTOR}$, NF- $\kappa \beta$, carbonic anhydrase, sphingosine kinase, $\mathrm{Na}^{+} / \mathrm{K}^{+}$-ATPase and CDK [24].

\section{Synthesis of 2-aminothiazole containing compounds}

To date, there are many methods for the preparation of 2aminothiazole and their derivatives such as Hantzsch, Cook Heilborn, and Tchernic have been reported [25]. The first and most frequently used method is Hantzsch's synthesis [26], who originated it in 1887 , involving the reaction of $\alpha$-halo carbonyl compounds with thioureas or thioamides in the presence of bromine/iodine, silica chloride, 1,3-di-nbutylimidazolium tetrafluoroborate, ammonium 12-molybdophosphate, and cyclodextrin, aq. $\mathrm{NaICl}_{2}$ or using various homogenous and heterogonous catalysts (Fig. 2) [27-29]. Another method of $\mathbf{6}$ preparations involves condensation rhodanamine $\left(\mathrm{H}_{2} \mathrm{~N}-\mathrm{SCN}\right)$ with the tenfold excess of ethyl acetoacetate in a melt at $100-120^{\circ} \mathrm{C}$ [30]. Condensation of ethyl acetoacetate with formamidine disulfide hydrobromide was performed analogously, providing 6 in $57-62 \%$ yield [31]. Carbonyl compounds and thiourea can be combined directly into the thiazole ring using bromine as the condensing agent [32]. Reaction of ethyl $\beta$-ethoxyacrylate with $N$ bromosuccinimide (NBS) produces a novel intermediate, $\alpha$ bromo- $\alpha$-formylacetate hemiacetal. Cyclization of the in situ formed hemiacetal with thioureas, also afforded 2aminothiazole-5-carboxylates [33]. Moreover, reaction of the trichloroether with diethylene glycol gives the cyclic acetal, which may also be converted to 2-aminothiazole (Fig. 3) [34].

In the last decades, a large amount of efforts inflected to design and discovery of compounds with improved anticancer activity derived from 2 -aminothiazole scaffold. In this paper, we have reviewed and highlighted the progresses of 2-aminothiazole core to pursuit potent anticancer agents. Accordingly, we have classified the reported compounds based on the type of the attached group to the 2-amino of 
2-aminothiazole framework includes amide, urea and thiourea, alkylamino, arylamino, amino-pyridine, aminopyrimidine schiff base, and hydrazone moieties. The information will useful for future innovation.

\section{Structural modification of 2-amine group of 2-aminothiazole framework}

\section{Modification of 2-amine to 2-amide}

2-aminothiazole compounds containing amino group in amide form are a large group to be investigated. Recently, using progesterone as the starting material, Fan and coworkers prepared a new class of steroidal derivatives with a Dring substituted benzamidothiazole. Characterization of these structures was performed by NMR and HRMS spectrometry. These derivatives were assessed for their antiproliferative activity on human prostate (PC-3) and ovarian (SKOV-3) cancer cell lines. Based on preliminary results, compounds $\mathbf{7 a}, \mathbf{7 b}$, and $\mathbf{7 c}$ showed moderate antiproliferative activity. Other bioactivities of these derivatives and structure modification of them are under investigation (Fig. 4) [35].

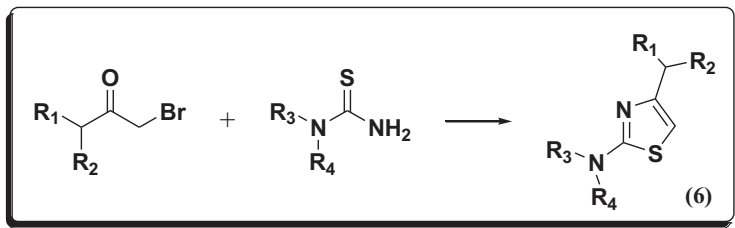

Fig. 2 General reaction for Hantzsch's synthesis of 2-aminothiazole
In a study by El-Messery et al. a novel series of 2acetamido- and 2 or 3-propanamido-thiazole analogs was designed and synthesized. At a single dose of $10 \mu \mathrm{M}$, these aminothiazoles bearing straight and branched substituent with different carbon chain length were subjected to NCI in vitro assessment for their antitumor activity. Among tested compounds, $\mathbf{8 a}, \mathbf{8 b}$, and $\mathbf{8 c}$ showed better antitumor activity with broad spectrum. Compound $\mathbf{8 a}$ is the most active one and exhibited moderate activity on colon, melanoma, renal, and breast cancer cell lines. Compounds 8d, 8e, 8f, and 8a exhibited considerable GI values; 75.5, 69.3, 96.2, and $92.7 \%$ against the Leukemia cell line, respectively. The obtained results showed that the introduction of 3-propanamido function (acyl chain of three carbon length) to the 2-aminothiazole core improved activity more than 2acetamido moiety (acyl chain of two carbon length). Also, antitumor results of the aliphatic substituted thiazoles and the aromatic congeners comparison showed that the aromatic substitution improved the antitumor activity more than 4- or 5-methyl; 4-methyl and 5-ethyl carboxylate derivatives, as exemplified in compound $\mathbf{8 a}$ with its broadspectrum antitumor activity against nearly all 60 cell lines used in this study (Fig. 4) [36].

In another work towards the development of effective VEGFR-2 inhibitors, Abou-Seri and coworkers synthesized new series of piperazinyl-thiazole acetamide scaffold. Among tested compounds, 9 particularly inhibited VEGFR2 at submicromolar $\mathrm{IC}_{50}(0.40 \pm 0.04 \mu \mathrm{M})$ and proved to be the most potent anticancer between these agents. According to results, compound 9 showed high selectivity against leukemia and prostate cancer exhibited subpanel MG-MID $\mathrm{GI}_{50}$ value of 3.51 and $5.15 \mu \mathrm{M}$, respectively. Molecular

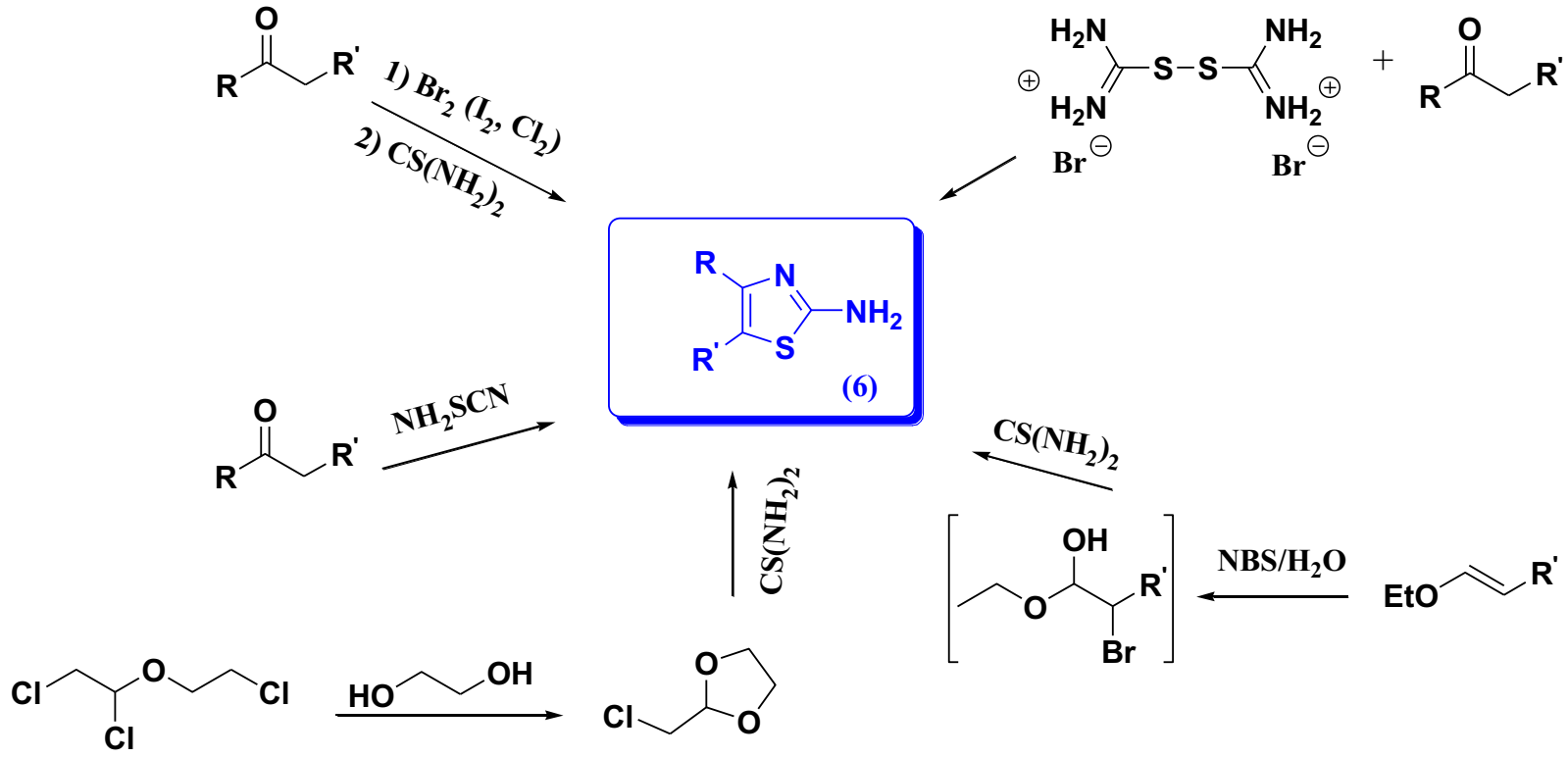

Fig. 3 Various synthetic routes to the 2-aminothiazole core preparation 


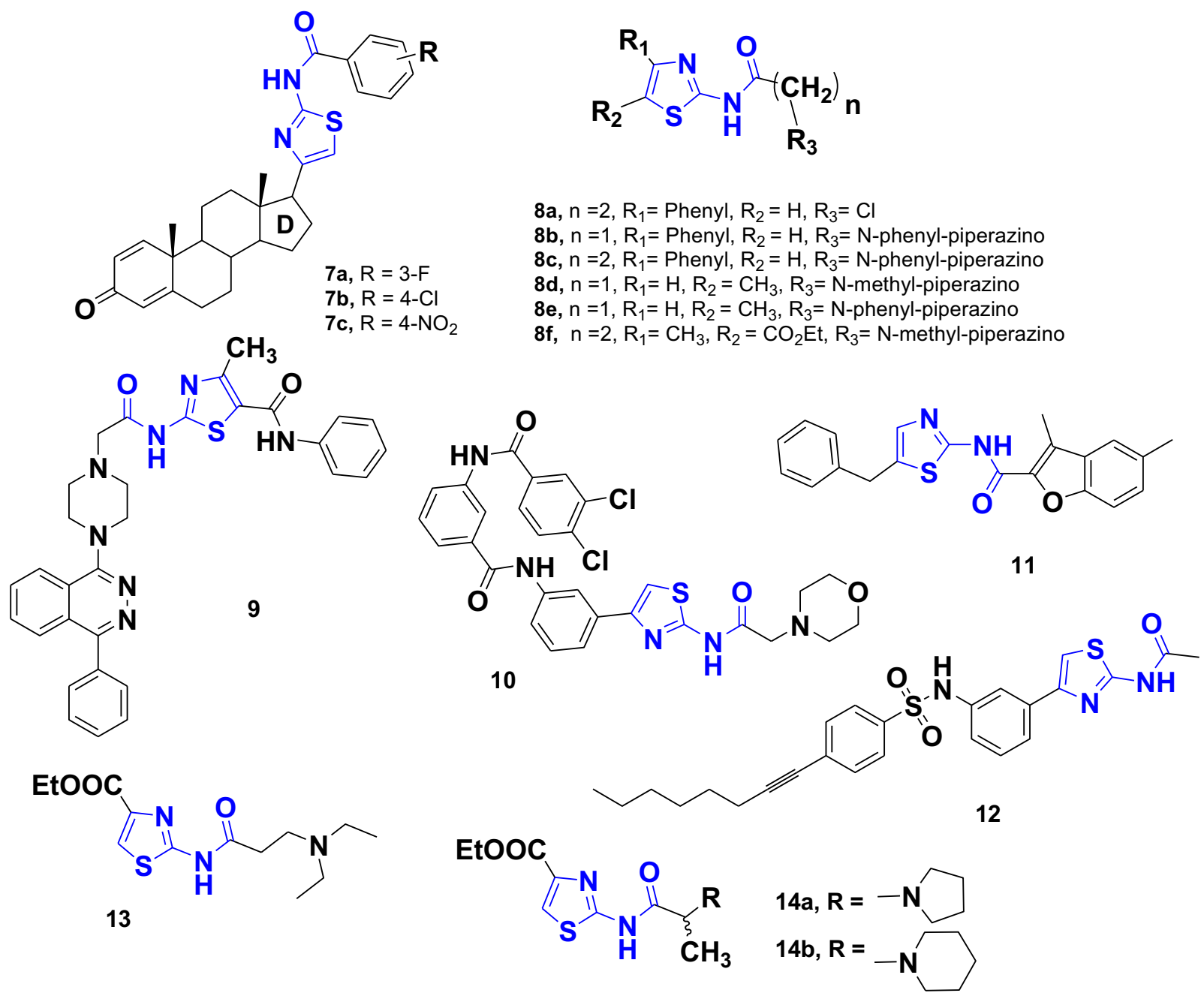

Fig. 4 2-Aminothiazole scaffold containing amide moiety (7-14)

docking studies of this compound revealed its potential binding mode into VEGFR-2 active site. In compound $\mathbf{9}$, an essential hydrogen bond was made by the $\mathrm{N}-\mathrm{H}$ of the acetamide and Glu885 in the active site. Also, arene interactions were formed between the phthalazine with Leu840, the piperazine ring with Phe1047, the thiazolyl rest with Ile1044 and Asp1046. The piperazinyl moiety interacted with Phe1047 within the active site. The 5- phenylcarboxamide in 9 was placed within a lipophilic pocket that may show more biological activity than other synthesized derivatives. Substitution on the pendant aryl moiety with large lipophilic group appeared to be the most important factor affecting the activity of these series (Fig. 4) [37].

Zhang and coworkers designed and synthesized 2amino-4-phenylthiazole derivatives. The compounds were screened for in vitro antiproliferative activity against four cancer cell lines containing A549, HeLa, HT29, and Karpas299 human cancer cell lines. Some of these synthesized compounds displayed remarkable antiproliferative activity.
Among these derivatives, compound 10 exhibited outstanding growth inhibitory effects against A549, HeLa, HT29, and Karpas299 cancer cell lines, especially for HT29 cells $\left(\mathrm{IC}_{50}=2.01 \mu \mathrm{M}\right)$. Based on in vitro activity of target compounds, the meta-halogen- (especially chloro-) on benzene ring improved anticancer activity and 3,4-diClor 3-Cl-benzene ring exhibited better inhibitory activity than 2,4-diCl substitution. According to the biological assay and a molecular docking analysis suggests that these compounds can be identified as a potential inhibitors (Fig. 4) [38].

In a study by Finiuk et al., new N-acylated-2-amino-5benzyl-1,3-thiazoles were prepared and assessed for their in vitro anticancer activity. The selectivity of tested compounds against glioblastoma and melanoma were proved in MTT assay and among these compounds, compound $\mathbf{1 1}$ demonstrating a selective action towards the human glioblastoma U251 cells and human melanoma WM793 cells, comparing to the leukemia cells. Meantime, these 
compounds created low toxicity to pseudo-normal cells (Fig. 4) [39].

In purpose to find novel active scaffold against sensitive and resistant cancer cells, Millet and coworkers reported the synthesis and evaluation of a novel bioactive molecules belonging to the $\mathrm{N}$-(4-(3-aminophenyl(thiazol-2-yl)acetamide family. The synthesized derivatives were evaluated against both sensitive and resistant cell lines of melanoma, leukemia, and pancreatic cancer cells. All tested compounds exhibited an activity in the range of medium to low micromolar. The lead compound 12 exhibited high in vitro cellular activities against melanoma, pancreatic cancer, and chronic myeloid leukemia and displayed a good selectivity against three cancer cells at its active concentration. Compound $\mathbf{1 2}$ also showed no toxicity against normal cells and good pharmacokinetic profiles. Derivative 12 delayed remarkably tumor growth on A375 xenograft model in mice (in vivo) and promoted cell death using apoptotic and autophagic deaths. According to SAR studies, aliphatic substituents in para-position of this scaffold were better tolerated. In the para-position of scaffold, there was a clear correlation between the size of the nonpolar substituent and the activity. The best compounds had a hydrophobic aliphatic chains or bulky iodine atom (Fig. 4) [40].

El-Subbagh et al. prepared and evaluated some new ethyl 2-substituted-aminothiazole- 4-carboxylate derivatives for their antitumor activity against 60 human tumor cell lines. Compound 13 indicated significant activity toward RPMI8226 leukemia cell line $\left(\mathrm{GI}_{50}=0.08 \mu \mathrm{M}\right)$, and showed a wide spectrum activity against a set of 60 different human cells with $\mathrm{GI}_{50}$ (MG-MID) value of $38.3 \mu \mathrm{M}$. According to a comparison between the known antineoplastic agent melphalan and derivative 13, melphalan showed more activity than analogue $\mathbf{1 3}$ in all tested cell lines except the higher activity of compound $\mathbf{1 3}$ against colon cancer cell lines and leukemia RPMI-8226 cell line. Based on the SAR studied, in the 2-aminoacetamide series, only derivatives with morpholino group or N-phenylpiperazino exhibited activity against MOLT-4 leukemia cell line. Compound with Nphenylpiperazino was more active than morpholino derivative and this derivative affect on another cell lines of SNB-19 CNS cancer and IGORV1 ovarian cancer. In the 3aminopropanamido series, compound $\mathbf{1 3}$ with diethylamino was the most active member with particular sensitivity toward six different cell lines and exchange of pyrrolidino, piperidino, morpholino, and $\mathrm{N}$-methylpiperazino with the diethylamino moiety in $\mathbf{1 3}$, decreased a nearly 2-3 fold the antitumor activity. In the 2-aminopropanamido series, only derivatives $\mathbf{1 4 a}$ with pyrrolidino and $\mathbf{1 4 b}$ with piperidino displayed significant activity against the leukemia cell lines RPMI-8226 and SR. Among these three series, the 3aminopropanamido series were more potent than the others. The results exhibited that compound $\mathbf{1 3}$ is a promising lead for further development to characterize the scope and limitation of its activity (Fig. 4) [41].

In a study in 2016, Zhu and coworkers assessed antitumor activity of TH- 39 (15) against K562 cells by immunoblot, co-immunoprecipitation, MTT assay, and flow cytometry. TH- 39 (15) showed $\mathrm{IC}_{50}$ value of $0.78 \mu \mathrm{M}$ against K562 cells. Mechanism studies exhibited that TH39 (15) may prevent the interaction of Hec1 and Nek2 in K562 cells. These compounds inhibited cell proliferation by G0/G1 cell cycle arrest and apoptosis induction in K562 cells in concentration and time dependently. Apoptosis induction was associated with caspase-3 activation, Bcl-2 down-regulation, and Bax up-regulation. TH-39 (15) also increased ROS accumulation and diminished mitochondrial membrane potential in K562 cells. According to the results, this compound might create apoptosis induction using the ROS-mitochondrial apoptotic pathway. Therefore, this study exhibited the potential therapeutic efficacy of TH-39 as an anti-cancer compound for treatment of chronic myeloid leukemia (Fig. 5) [42].

High throughput screening found compound 16a as an inhibitor of CDK2. Due to the inactivation of this compound (16a) in cells and instability in plasma, kim et al. have converted it to compound $\mathbf{1 6 b}$ using replacing the ester and a 5-ethyl-substituted oxazole. Most of 100 derivatives with $\mathrm{IC}_{50}$ values in the range of $1-10 \mathrm{nM}$ were rapidly synthesized. Many of these derivatives exhibited in vitro potential activity and showed broad-spectrum antiproliferative activity against a set of tumor cells. In addition, CDK2 inhibitors of this class created rapid apoptosis in A2780 ovarian carcinoma cells. Compound $\mathbf{1 6}$ b showed potential cytotoxicity against a diversity of cell lines and in the presence of this compound decreased the phosphorylation of $\mathrm{CDK} 2$ substrates that containing $\mathrm{RB}$, histone $\mathrm{H} 1$, and DNA polymerase R in A2780 cells. Based on cell cycle analysis, compound 16c reduced cell population in $\mathrm{S}$ phase in A2780 cells and largely increased apoptotic fraction. Compound 16d proved a good pharmacokinetic profile and solubility in mice and illustrated high in vivo antitumor activity in many murine and human models (Fig. 5) [43].

Considering 2-aminothiazole as a key building block, Kim et al. found that (E)-N-(5-benzylthiazol2-yl)-3-(furan2-yl)acrylamide $\mathbf{1 7}$ showed potent anticancer activity and proteomics approaches were assumed to recognize the target protein of compound 17, importin b1 (KPNB1). According to a competitive binding assay by fluoresceinlabeled 17, compound 17 exhibited high binding affinity for KPNB1 with $K_{\mathrm{d}}$ value of $\sim 20 \mathrm{~nm}$. Compound 17 displayed inhibitory activity on the importin pathway that was confirmed by western blotting assays for KPNB1, KPNA2, EGFR, ErbB2, and STAT3. Some inhibitors have not penetrated in the cells and a wide range of $K_{\mathrm{d}}$ were obtained for these inhibitors (single-digit micromolar to many 
<smiles>CCOC(=O)CSc1cnc(NC(C)=O)s1</smiles><smiles>COc1cc(C(=O)c2ccc(-c3csc(NC(=O)C(N)C(C)Cl)n3)cc2-n2cncn2)cc(OC)c1OC</smiles>

17

18

19<smiles>Cc1ccc(CNCCC(=O)Nc2nc3c(s2)CCCC3)cc1</smiles><smiles>Cc1cccc(Cl)c1NC(=O)c1cnc(NC(=O)CN2CCN(C)CC2)s1</smiles>

20<smiles>CC(C)Cc1cnc(CSc2cnc(NC(=O)Cc3ccc(CNC(CO)CO)cc3)s2)o1</smiles>

21

22

Fig. 5 2-Aminothiazole scaffold containing amide moiety (15-22)

hundred micromolar). Overexpression of KPBN1 occurred in many cancer cells whereas siRNA-induced inhibition of KPNB1 significantly inhibited proliferation of cancer cells, while did not affect normal cells. A pyrrole compound, importazole, karyostatin $1 \mathrm{~A}$, peptides, and small proteinlike peptidomimetics with binding to KPNB1 inhibited the classical importin pathway. Consequently, compound $\mathbf{1 7}$ as a potent and promising lead could be used for the development of KPNB1-targeted anticancer compounds. Fluorescein-labeled $\mathbf{1 7}$ as a useful quantitative probe could be applied for the identification and development of new KPNB1 inhibitors (Fig. 5) [44].

A new series of 2-arylamido and 2-alkylamido derivatives of 2-amino-4 (isothiocyanatomethy1) thiazole were synthesized and evaluated for their in vitro antiproliferative activity using L1210 cells. The 2-(alkylamido) thiazole analogues exhibited moderately antiproliferative activity with $\mathrm{IC}_{50}$ value of 4-8 $\mu \mathrm{M}$ and for the arylamido derivatives were obtained a remarkable increase in antiproliferative activity with $\mathrm{IC}_{50}$ value of $0.2-1 \mu \mathrm{M}$. Compound 18 (2Benzamido-4-(isothiocyanatornethyl)- thiazole) showed a potential inhibitory against GMP synthetase. Introducing both electron-withdrawing and electron-donating on the benzene ring in due to explore the possibility of further enhancing the activity of this lead compound (18), was showed that electronic impacts in the benzene ring were not an important determinative of antiproliferative activity for this compound. To seek the importance of the 4-(isothiocyanatomethyl) substituent in compound 18, the mentioned group was replaced with a 4-chloromethyl moiety on 2-acetamidothiazole and the 2-benzamidothiazole. None of these compounds showed an increase in activity. 
Thus, it revealed that the isothiocyanatomethyl role was important for the antiproliferative activity of this compound (Fig. 5) [45].

Tubulin polymerization inhibitors had emerged as one of promising anticancer therapeutics because of their dual mechanism of action, i.e. apoptosis by cell-cycle arrest and vascular disrupting agent. In a study in 2010, Lee and coworkers have used benzophenone core to identify new tubulin inhibitors with potent cytotoxicity and strong tubulin polymerization inhibition as strong in vivo antitumor activity. A number of derivatives were synthesized by introduction of small heterocycles in B-ring of the structure and were assessed for their in vitro cytotoxicity, inhibition of tubulin polymerization, and in vivo antitumor activity. According to the results, compound $\mathbf{1 9}$ (a valine prodrug) indicated potential cytotoxicity against some cancer cells such as P-gp overexpressing MDR positive cell line (HCT15). Inhibitory activity of compound 19 on tubulin polymerization significantly induced cell cycle arrest at G2/M phase of HL60 cells. Therefore, Compound 19 with improved aqueous solubility displayed significant antitumor activity against murine tumors and human xenogratfs in mice dose-dependently. This analogue (19) with good profiles was assessed in preclinical toxicology studies and improved to phase 1 clinical trial. The SAR studies indicated that trimethoxy groups in the A-ring of structure are critical for in vitro activity (Fig. 5) [46].

2-aminothiazole sublibrary with lipophilic substituents (such as methyl, bromo, phenyl, or butylidene) at 4- or/and 5 -position of scaffold were synthesized and tested for antitumor activities against two cancer cell line of human lung cancer (H1299) and human glioma (SHG-44). Some compounds exhibited moderate to good activities against two cancer cell lines. Among these compounds, the promising analogue 20 illustrated the most potent antitumor activities with $\mathrm{IC}_{50}$ values of 4.89 and $4.03 \mu \mathrm{M}$ against H1299 and SHG-44 cell lines, respectively. The SARs analysis indicated that 2-aminothiazoles containing 4,5butylidene and benzylic amines were benefit for improvement the cytotoxicity of the synthesized compounds. The incorporation of methyl group at the $\mathrm{C}_{4}$ - or $\mathrm{C}_{5}$-position of the thiazoles core decreased potency $\left(\mathrm{IC}_{50}>10 \mu \mathrm{mol} / \mathrm{L}\right)$. Introducing the phenyl group at $\mathrm{C}_{4}$-position of the thiazole had the similar substituent effect on the potency. The exchange of methyl unit with bromo group at the C5position of the thiazoles led to the $\mathrm{IC}_{50}$ values range of 6.61 to $9.34 \mu \mathrm{M}$. Therefore, 4,5,6,7 tetrahydrobenzo[ $d]$ thiazoles core can be used as promising antitumor agent at level of micromolar (Fig. 5) [47].

In an attempt to develop potent and selective anti-tumor drugs, a number of novel 2-amino-thiazole-5- carboxylic acid phenylamide derivatives based on the structure of dasatinib were designed and synthesized by Liu et al. According to biological evaluation results, compound $\mathbf{2 1}$ indicated potent and selective antiproliferative activity against human K563 leukemia cells $\left(\mathrm{IC}_{50}=16.3 \mu \mathrm{M}\right)$ compared with dasatinib $\left(\mathrm{IC}_{50}=11.08 \mu \mathrm{M}\right)$. Compound $\mathbf{2 1}$ was inactive against MDA-MB 231 and clearly less active against MCF-7 and HT-29 with $\mathrm{IC}_{50}$ values of 20.2 and $21.6 \mu \mathrm{M}$, respectively but dasatinib at each cell line indicated $\mathrm{IC}_{50}$ value of $<1 \mu \mathrm{M}$. Therefore, replacement of pyrimidin-4-ylamino core in dasatinib with an acetylamide drastically reduced the antitumor activity against solid tumors but compounds $\mathbf{2 1}$ with acetylamide group indicated good selectivity against human K563 leukemia cells (Fig. 5) [48].

Misra et al. synthesized a novel class of $N$-Acyl-2-aminothiazoles with non-aromatic acyl side chains and evaluated their biological activity. These series of compounds were identified as potent and selective CDK2/cycE inhibitors that showed antitumor activity in mice. Modification of reported analogue 22 was performed with replacement of an aromatic acyl side chain with a nonaromatic amino acyl side chain and reduced protein binding, molecular weight, and in vitro metabolism in liver and improved aqueous solubility. The acyl side chain expanded into the hydrophilic extra protein space. Investigation of potency, pharmacokinetics properties, and assessment in both models of an ip/ip P388 murine tumor model and an A2870 human ovarian cancer xenograft tumor mouse model identified the compound 2. SNS-032 (formerly BMS-387032) (2) was found as an ATP-competitive and CDK2- selective inhibitor that were selected as an antitumor agent to enter in Phase 1 human clinical trials. Analogue 2 inhibited a $\mathrm{CDK} 2 / \mathrm{cycE}$ with $\mathrm{IC}_{50}$ value of $48 \mathrm{nM}$. It also exhibited strong selectivity against over a panel of 12 unrelated kinases. In an A2780 cellular cytotoxicity assay, compound 2 indicated antiproliferative activity with $\mathrm{IC}_{50} 95 \mathrm{nM}$. Plasma half-life was obtained 5-7 h in three species for $\mathbf{2}$ and exhibited relatively low protein binding in mouse and human serum (69 and 63\%, respectively). Compound 2 illustrated $100 \%, 31 \%$, and $28 \%$ bioavailability in mouse, rat, and dog, respectively (Fig. 5) [49].

In continuation of previous work to find the newly anticancer agents, in a study in 2014 Nofal et al. prepared some new series of thiazole derivatives and investigated their cytotoxic activity against two different cancerous cell lines HepG2 and PC12. Among these analogues, compounds 23 and $\mathbf{2 4}$ exhibited a dual antitumor efficacy against $\mathrm{PC} 12$ and $\mathrm{HepG} 2$ cell lines with $\mathrm{IC}_{50}$ values of 0.51 and $0.57 \mathrm{mM}$ for HepG2 cell lines and 0.309 and $0.298 \mathrm{mM}$ for PC12 cell lines. Introduction of a chlorine atom on 2amino group of the thiazole ring or its addition to a dialkyl group exhibited a significant decrease in the activity and with enhancement in the molecular volumes reduced the activity (Fig. 6) [50].

In another work, a new series of benzothiazole and thiazole-based hydroxamic acids were reported by Tung 
<smiles>O=C1c2ccccc2SC(c2ccc(F)cc2)N1c1nc(-c2nc3ccccc3[nH]2)cs1</smiles><smiles>CN(C)CC(=O)Nc1nc(-c2nc3ccccc3n2C)cs1</smiles>

24<smiles>CC(C)(C)c1nc(NC(=O)CN2CCCCC2)sc1Cc1ccc(Cl)cc1</smiles><smiles>[R]c1ccc2nc(NC(=O)C(=O)NO)sc2c1</smiles>

25a, $\mathrm{R}=6-\mathrm{Cl}$

$25 \mathrm{~b}, \mathrm{R}=6-\mathrm{CF}_{3}$<smiles>O=C(NO)C(=O)Nc1nccs1</smiles><smiles>O=C(CN1CCOCC1)Nc1nc(-c2ccc(NC(=O)c3ccc(Cl)c(Cl)c3)cc2)cs1</smiles>

26<smiles></smiles>

29<smiles>[R]c1ccc(N=Nc2sc(NC(=O)CCCCCC)nc2C)cc1</smiles>

33<smiles>Cc1cc(C)nc(SCC(=O)Nc2ncc(Cc3cccc4ccc(Cl)cc34)s2)n1</smiles><smiles>Nc1nc(SCC(=O)Nc2nc3ccc(S(N)(=O)=O)cc3s2)nc2[nH]ncc12</smiles>

$31 \mathrm{~b}, \mathrm{R}=\mathrm{NO}_{2}$

31c, $\mathrm{R}=\mathrm{OCH}_{3}$<smiles>CCN(CC)CCC(=O)Nc1nc2ccc(-c3cnc(OC)c(NS(=O)(=O)c4ccc(F)cc4)c3)cc2s1</smiles>

34

Fig. 6 2-Aminothiazole scaffold containing amide moiety (23-34)

et al. Some compounds exhibited strong anticancer cytotoxicity. These derivatives remarkably inhibited histone deacetylase (HDAC) activities that enhanced histone acetylation in Hela cells. All tested compounds indicated high cytotoxicity against a panel of human cancer cell lines. Compounds 25a, 25b, and 26 significantly inhibited HDAC. Based on docking studies, compounds 25a, 25b indicated slightly higher affinities to HDAC8 in comparison to SAHA (has been approved by the FDA for the treatment of T-cell lymphoma). Compound 25a showed equal cytotoxicity compared to SAHA on five cancer cell lines and illustrated equivalent efficacy compared to SAHA in PC-3 mouse xenograft model. Tumor growth inhibition rate of 25a was obtained $49.0 \%$ at $30 \mathrm{mg} / \mathrm{kg}$ that was comparable to SAHA (48.3\%) at the same dose (Fig. 6) [51].

$\mathrm{Wu}$ and coworkers designed and prepared a number of new N-(5-benzyl-4-(tert-butyl) thiazol-2-yl)-2-(piperazin-1yl)acetamides. These derivatives were evaluated for their in vitro antitumor activities against three cell lines the A549, HeLa, and MCF-7 cell lines. Among tested compounds, compound 27 indicated strong antiproliferative activity against two cancer cell lines HeLa and A549. Compound 27 exhibited most inhibitory activity on HeLa cells with $\mathrm{IC}_{50}$ value of $1.6 \pm 0.8 \mu \mathrm{M}$. Compound 27 was selected for investigation of morphological analysis in the HeLa cell line using acridine orange (AO)/ethidium 
bromide (EB) double staining and cell cycle analysis using flow cytometry on the HeLa cell line. According to the results, compound 27 could cause cell apoptosis induction and G1-phase arrest in the cell cycle of HeLa cells. The SAR studies revealed that $\mathrm{R}$ significantly effects on antitumor activities of compounds. When $\mathrm{R}$ replaced with $\mathrm{C}_{6} \mathrm{H}_{5}$, 4- $\mathrm{C}_{6} \mathrm{H}_{4} \mathrm{OH}$ and $\mathrm{C}_{2} \mathrm{H}_{5}$ groups exhibited the best activity against A549 cells, HeLa cells, and MCF-7 cells, respectively. The introduction of piperazine in the structure remarkably increased antitumor activity. Replacement of X with $\mathrm{Cl}$ in the para-position of phenyl created most activity against three A549 cells, HeLa cells, and MCF-7cell lines (Fig. 6) [52].

The research group of Zhang designed and prepared a number of new 2,4-disubstituted thiazole amide derivatives according to crizotinib as a c-Met/ALK inhibitor. These derivatives were evaluated their antiproliferative activities. Several tested compounds showed medium to good antiproliferative activity against four cancerous cell lines A549, HeLa, HT29, and Karpas299 cells. Among these derivatives, compound 28 indicated inhibitory against A549, HeLa, HT29, and Karpas299 cells with $\mathrm{IC}_{50}$ values of 8.64, $6.05,0.63$ and $13.87 \mu \mathrm{M}$, respectively. According to the SAR studies on R group, in terms of cellular activities, the meta-halogen showed better antitumor activity to the metamethyl on phenyl ring. The activity of different chlorosubstitution positions on the phenyl ring order was $m-\mathrm{Cl}>$ $3,4-\mathrm{Cl}_{2}>2,4-\mathrm{Cl}_{2}$. A moderate polar function on the phenyl ring was harmful for anticancer activities. When the phenyl ring was replaced by furan ring, the activity was obtained worse than compound 28. Introduction of the alkyl group on the phenyl ring decreased activity against tested cell lines. In the binding mode, compound $\mathbf{2 8}$ was incorporated in binding pocket of the crizotinib. A hydrogen bond was formed by the 2-morpholinoacetamido fragment and Asp1164 and a $\pi-\pi$ interaction was formed between the thiazole ring and Met1160. The 2-morpholinoacetamido in derivative $\mathbf{2 8}$ and the substituted phenyl ring in crizotinib occupied a similar position of binding pocket. These results provide important clues for further optimization of compound $\mathbf{2 8}$ as a potential c-Met inhibitor (Fig. 6) [53].

Lee and coworkers designed and prepared a number of 4aryl-N-arylcarbonyl-2-aminothiazoles as Hec1/ Nek2 inhibitors. Compound 29 indicated potent in vitro antiproliferative activity with $\mathrm{IC}_{50}$ range of $16.3-42.7 \mathrm{nM}$, good pharmacokinetic profiles in SD rats, remarkable in vivo antitumor activity in mice with human MDA-MB-231 xenografts and while showed less activity against normal cells, kinases, and hERG. Based on cell responses resulting, compound 29 inhibited Hec1/Nek2 in cells using a decreased level of Hec1 co-immunoprecipitated with Nek2, Nek2 degradation, mitotic abnormalities, and apoptosis induction. This compound exhibited good selectivity against cancer cells while was not active toward normal cells. In the Herg liability screening, compound $\mathbf{2 9}$ did not show activity in a $\left[{ }^{3} \mathrm{H}\right]$ astemizole competitive binding assay $\left(\mathrm{IC}_{50}>10 \mu \mathrm{M}\right)$. The SAR studies indicated that exchange of the 4-pyridyl group with a 4-cyanophenyl group created about twofold decreased potency against three cell lines K562, MDA-MB-468, and MDA-MB-231. When the pyridyl group converted to pyridyl N-oxide, potency reduced more than fourfold $\left(\mathrm{IC}_{50}: 2.7\right.$ to $\left.>10 \mu \mathrm{M}\right)$. Insertion of an ortho-chloro or ortho-fluoro group at the 4-pyridyl group slightly decreased potency $\left(\mathrm{IC}_{50}=0.42-0.77 \mu \mathrm{M}\right)$. The introduction of an alkoxy group at the C-4' position of $\mathbf{2 9}$ increased antiproliferative activity. Insertion of methoxy, ethoxy, i-propoxy, i-butoxy, and c-pentoxy groups at the C$4^{\prime}$ position of 29 enhanced antiproliferative activity than a $\mathrm{C}-4^{\prime}$ methyl group, with $\mathrm{IC}_{50}$ range of $42.1-392 \mathrm{nM}$. The alkoxy groups in scaffold 29 were replaced with aryloxy groups. C-4' phenoxy replacement with the c-pentoxy group exhibited a similar potency. The introduction of 3,5-dimethyls at the phenoxy group eliminated activity. A similar activity was seen in presence of a 4-fluorophenoxy, 4-metyl and 4-ethyl phenoxy group at C-4' position. Introduction of C-4' 4-methoxyphenoxy demonstrated potential antiproliferative activity against the four cancer cell lines $\left(\mathrm{IC}_{50}\right.$ $=32.0-48.6 \mathrm{nM}$ ) and movement of the C-4 methoxy group to the $\mathrm{C}-3$ position of phenyl ring decreased the antiproliferative activity. Bearing a $2^{\prime}, 6^{\prime}$-difluoro group at the 4pyridyl group reduced in vitro activity compared to its $2^{\prime}, 6^{\prime}$ dimethyl derivatives. Introducing an ortho-fluoro atom at the pyridyl group increased in vitro antiproliferative activity with $\mathrm{IC}_{50}$ value of $16.3-42.7 \mathrm{nM}$ (Fig. 6) [54].

Sirtuins are $\mathrm{NAD}^{+}$-dependent protein deacylases that cleave off acetyl, but also other acyl groups from the $\varepsilon$ amino group of lysines in histones and other substrate proteins. Disregulation of human Sirt2 (hSirt2) activity has been associated with the pathogenesis of cancer, which makes the modulation of hSirt2 activity a promising strategy for pharmaceutical intervention. In continuation the previous work, Schiedel et al. recently discovered the Sirtuin Rearranging Ligand (30) as very potent and selective $\mathrm{hSirt} 2$ inhibitors. In this work, they investigated structureactivity relationship of SirReals (the sirtuin rearranging ligands) that rationalizes the unique features of this compound and search the modifications limits on this scaffold. As specified in the structure, the 4,6-dimethylpyrimidine moiety was important for the binding of the ligand to formed 'selectivity pocket'. However, a switch from the aminothiazole to the aminothiadiazole scaffold was shown to lead to a loss in potency. In the absence of the methyl groups at the 4 and/or 6 position of pyrimidine ring, led to lose its affinity. Presence of bulky groups or high degree of methylation decreased potency and presence of polar substituents at the pyrimidine ring such as $-\mathrm{OH}$ or $-\mathrm{NH}_{2}$, did 
not improved potency. The ligands with 1- naphthyl substituted showed the superiority to substituted phenyl moieties or 2-naphthyl, biphenyl. Insertion of a substituent at the 4- position of the phenyl was unfavorable because of the proximity of Phe234, but the substituent in the 3-position of the phenyl was tolerated within the acyl-lysine channel. Most importantly, chlorination or bromination of the naphthyl in position 7 improved the in vitro activity. The 7halonaphthyl substituent fills the lipophilic naphthyl binding site more efficiently than the unsubstituted naphthyl moiety, and thereby allows further hydrophobic interactions. The carbonyl-O of the amide also forms a watermediated hydrogen bond to the backbone carbonyl-O of Pro94. Also, an intramolecular hydrogen bond between the amide $\mathrm{N}-\mathrm{H}$ and one of the nitrogen atoms of the dimethylpyrimidine ring has formed. It is clearly demonstrated that the presence of all three functional elements, namely: arylmethyl, aminothiazole, and 4,6-dimethylpyrimidine are crucial for efficient inhibition of hSirt2 activity (Fig. 6) [55].

A number of 5-arylazoaminothiazole analogues were efficiently synthesized in good yields by Al-Anazi and coworkers. Afterward, the synthesized derivatives were tested against four cell lines HepG2, HEp-2, PC3, and MCF-7 as cytotoxic agents. Analogues 31a-c displayed high cytotoxicity. Compound 31c exhibited the similar cytotoxicity to 5-fluorouracil against PC3 cell line and showed lower cytotoxicity against other cells compared to 5-fluorouracil. According to SAR studies, the introduction of methoxy unit as an electron donating group may improve the cytotoxicity compared to presence of nitro unit as an electron withdrawing group. The incorporation of chloroacetyl substituent may enhance the cytotoxicity compared to the insertion of benzoyl or acetyl group (Fig. 6) [56].

The research group of Ibrahim designed, prepared, and investigated a novel set of 2-aminobenzothiazole analogues with sulfonamide at position 6 as inhibitors of four isoforms of the metalloenzyme carbonic anhydras including hCA I and II (antiglaucoma target) and hCA IX and XII (anti-tumor targets). Docking studies were performed to expose details regarding the desirable interactions between the cores of these new derivatives and the active sites of the CA isoforms. Most of the synthesized derivatives exhibited high inhibitory activity against the tumor-associated hCA IX and hCA XII with $K_{i}$ values in the nanomolar range. $K i$ values for inhibition of cytosolic isozyme hCA II was obtained in ranging from 3.5 to $45.4 \mathrm{nM}$. Compound 32 displayed a selective inhibition against CA XII that showing some heterocyclic moieties could be utilized for designing effective transmembrane tumor-associated hCA XII inhibitors, with high selectivity and activity (Fig. 6) [57].

$N$-(2-chloro-5-(2-acetylaminobenzo[ $d$ ]thiazol-6-yl)pyridin-3-yl)-4-fluorophenylsulfonamide (33) displays toxicity as a PI3K and mTOR dual inhibitor, when orally administrated. Xie et al. have replaced the acetamide group in the 33 with alkylurea moiety and a series of 1-alkyl-3-(6-(2,3disubstituted pyridin-5-yl)benzo[ $d]$ thiazol-2-yl)urea derivatives were synthesized. The in vitro antiproliferative activity of these derivatives were assessed against four human cancer cell lines HCT116, MCF-7, U87 MG, and A549 cell lines using MTT assay. The derivatives with high antiproliferative activity were examined for their acute oral toxicity and inhibition of PI3Ks and mTORC1.

According to the results, derivative with a 2-(dialkylamino)ethylurea moiety at the position 2 of benzothiazole retained the antiproliferative activity $\left(\mathrm{IC}_{50}=13 \mathrm{nM}\right.$ against $\mathrm{PI} 3 \mathrm{~K} \alpha$ ) against the four cancer cell lines and inhibition of PI3K and mTOR. Replacement of 2-acetylamino in compound $\mathbf{3 3}$ with akylamino showed a significant drop in the cell-based activity. Therefore alkylamino is not a suitable substituent at the 2-position of benzothiazole core. Derivatives with a methoxy at the position 2 pyridine ring increased the antiproliferative effects. The presence of arylsulfonamino group at the position 3 of pyridine ring, such as 4-methylphenylsulfonamino, showed more activity than the presence of cyclopropylsulfonamino and the cyano groups at the position 3 of pyridine. The replacement of benzothiazole scaffold with thiazolo[5,4- $b]$ pyridine exhibited an better activity towards HCT-116 and MCF-7 cell lines and a close activity towards U87 MG and A549 cell lines. In the cell-based activity, derivative $\mathbf{3 4}$ had the comparable $\mathrm{IC}_{50}$ value to that of compound 33. Acute oral toxicity of these derivatives increased dramatically. Derivative $\mathbf{3 4}$ inhibited successfully tumor growth in a mice S180 homograft model. The results suggested that 1-(2dialkylamino)ethyl-3-(6-(2-methoxy-3-sulfonylaminopyridin-5-yl) benzo[d]thiazol-2-yl)urea analogues could use as strong PI3K inhibitors and anticancer compounds with low toxicity (Fig. 6) [58].

Regarding in vitro cytotoxicity and in vivo antitumor activity of girolline (35) as a natural antitumor compound Schiavi et al. synthesized 2-aminothiazole analogues of girolline. Because of undesired side effects of girolline, the phase I clinical trials have been discontinued. Thus, the synthesis of analogs might allow for improvement of its biological profiles. In this study, analogs were produced in two forms, threo (natural stereochemistry form) and erythro (non-natural form). They synthesized analogs in which the side chain of the natural product was preserved, while the 2aminoimidazole ring was replaced by a 2 -aminothiazole ring. This change was resulted into the most potent compounds 36a and 36b in this series. Prepared compounds were evaluated for their anticancer activity against KB cells, derived from an epidermoid carcinoma in the mouth of an adult Caucasian male. Compounds 36a and 36b have shown an interesting and unexpected in vitro activity; 100 
Fig. 7 Analogs of girollines; a natural antitumor agent

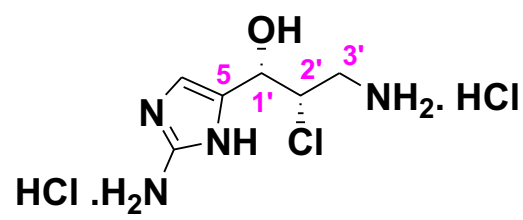

Girolline, 35

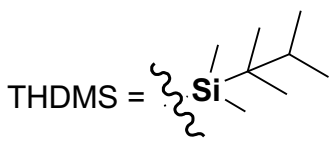

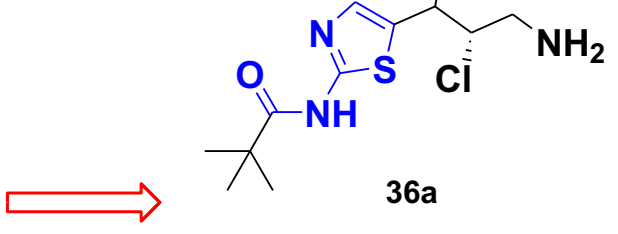

OTHDMS

Boc.HN<smiles></smiles>

and $85 \%$ inhibition, respectively. Presence of chlorine and nitrogen functional groups was known as necessary for their anticancer activity. Amine group performed the better activity than azide in the side chain. Also, 1'-hydroxy and 2amino groups must be protected (Fig. 7) [59].

\section{Modification of 2-amine to 2-urea and thiourea}

Considering $\mathrm{PI} 3 \mathrm{~K} \alpha$ as a key driver in a number of cancers through amplification, overexpression, and mutation one and the most commonly mutated genes in human cancer, Fairhurst and coworkers synthesized a new series of 4,5-dihydrobenzo[1,2-d:3,4-d]bisthiazole and 4,5-dihydrothiazolo [4,5-h]quinazoline tricyclic derivatives based on (S)-prolineamide aminothiazole-urea derivative alpelisib, which is currently one of the most advanced with Phase I/II clinical studies currently ongoing. Bisthiazole core analogues suggested an opportunity to increase the interaction within the ATP pocket of PI3K $\alpha$. A cyclization from the 4-methyl of the aminothiazole moiety, was anticipated to introduce additional favorable hydrophobic contacts within the affinity pocket with the side chain of tyrosine 836 and also locks the inhibitor in the conformation required for optimally interacting within the PI3K ATP-pocket. Synthesized derivatives were evaluated against an internal panel of 35 kinase assays, containing the lipid kinases phosphatidylinositol-4-kinase beta (PI4K $\beta), \mathrm{Vps} 34$ and mTor. All the derivatives did not show remarkable inhibition at concentrations $>10 \mu \mathrm{M}$ in used biochemical assays, with the exception of PI4K $\beta$ and Vps34. These data demonstrated a great PI3K $\alpha$ selectivity for this series and exhibited the PI4K $\beta$ selectivity at a similar to the class 1 PI3K family. Among tested derivatives, compounds $\mathbf{3 7}, \mathbf{3 8}, \mathbf{3 9}$, and $\mathbf{4 0}$ were found as in vivo potent and selective PI $3 \mathrm{~K} \alpha$ inhibitor. A way to enhance the affinity for the PI3K ATP-pocket was strengthen the interaction with Y836 that this annulation could create it. Low dose rat pharmacokinetic studies exhibited good oral exposures for this series in compared to their parent. Pharmacokinetic and pharmacodynamic studies for analogues in the mouse displayed that they were capable of inhibiting signaling via the PI3K pathway for higher than $8 \mathrm{~h}$, showing their potential in vivo PI3K $\alpha$ inhibitory activity (Fig. 8) [60].

Overexpression of VEGFRs serves as a potential target for anticancer agents. In addition, frequent occurrences of aberrant signaling mediated by PI3Ks in human cancers have made them attractive targets for the design of smallmolecule inhibitors. However, VEGFRs and PI3Ks are from different kinases families so it is a challenge to effectively design dual inhibitors of VEGFRs and PI3Ks. Based on this evidence, a series of compounds possessing 2-(3-phenyl) ureidothiazol-4-formamide derivatives with a 2-ureidothiazole scaffold were designed and synthesized by Li et al. (2016). Several compounds inhibited cell proliferation of both MDA-MB-231 and HepG2 cell lines than Sorafenib. Compound 41 exhibited good PI3K $\alpha$ inhibitory activity and moderate VEGFR-2 inhibitory activities with inhibitory rate of $36.58 \%$ and $58.44 \%$. According to SAR studies, presence of benzene and thiazole ring and removal of the methane function were important for the antitumor activity. Based on VEGFR-2 docking study, ligand 41 created one $\pi-\pi$ interaction and one cation $-\pi$ interaction and three hydrogen bonds. One hydrogen bond was formed between phenolic hydroxyl and CYS919 and other hydrogen bond was created by the urea hydrogen atom and GLU885. PHE918 and LYS868 formed the $\pi-\pi$ interaction and cation $-\pi$ interaction, respectively. According to the docking analysis of the PI3K-binding domain, three hydrogen bonds were formed by compound $\mathbf{4 1}$ and the protein that was containing phenolic hydroxyl oxygen and carbonyl oxygen with LYS833 and other hydrogen bond was observed between the urea group and VAL882. Compound 41 can be considered as a promising and potent VEGFR and PI3K inhibitor (Fig. 8) [61].

Considering the importance of 2-aminothiazole scaffold, Rostom and coworkers reported the synthesis of bifunctional thiazole compounds with amidic linker and evaluated 
<smiles>C[C@@H]1CCN(C(=O)Nc2nc3c(s2)-c2nc(C(C)(C)C(F)(F)F)sc2CC3)[C@@H]1C(N)=O</smiles>

37<smiles></smiles>

39<smiles>[R]NC(=S)Nc1nc(C(=O)NNC(=O)c2ccccc2)cs1</smiles><smiles>CN(C)C[C@@H]1CCN(C(=O)Nc2nc3c(s2)-c2nc(C(C)(C)C)sc2CC3)[C@@H]1C(N)=O</smiles><smiles>CN(C)C[C@]1(C(N)=O)CCCN1C(=O)Nc1nc2c(s1)-c1nc(C(C)(C)C)ncc1CC2</smiles>

40

Fig. 8 2-Aminothiazole scaffold containing urea and thiourea moiety (37-44)

for their anticancer activities. These analogues were subjected for their preliminary in vitro anticancer screening according to the current one-dose protocol of the NCI. Analogue 42 displayed a broad spectrum of anticancer effects. Besides, remarkable enhancement in activity against a wide range of subpanel tumor cell lines especially leukemia and melanoma subpanels was seen in due to derivatization of the 2-amino group into substituted ureido functionality as in $\mathbf{4 2}$. Furthermore, a noticeable reduction in the overall anticancer spectrum as a result of further 
derivatization of compound $\mathbf{4 2}$ into their corresponding acid hydrazides was shown. However, bioisosteric replacement of the ureido group with a thioureido led to an obvious reduction in the anticancer potency. Finally, an overall remarkable reduction in activity was reported because of changing the ester function into a substituted carboxamido group. Concertedly, analogue $\mathbf{4 2}$ could be used as promising dual anticancer antibiotics (Fig. 8) [62].

Some of 2,4-disubstituted thiazole derivatives have been synthesized and evaluated for their antitumor activity by the NCI in vitro disease-oriented antitumor screen. The tested compounds showed antineoplastic activity. All of the active compounds in the present study (43a, 43b, 44a and 44b) exhibited activity with $\mathrm{GI}_{50}$ values of $17.8,8.5,9.5$, and $7.4 \mu \mathrm{M}$, respectively and proved to be nonselective with broad-spectrum antitumor activity against the nine tumor subpanels used with ratios of $0.2-1.7$ for $\mathrm{GI}_{50}$ and $0.4-1.7$ for TGI.

Structure-activity correlations of the obtained antitumor screening data revealed that the 2-cyclohexyl-thioureido derivatives 44a and 44b are more active than their corresponding 2-n-butylthioureido compounds. It is worth mentioning that even though the n-butyl and cyclohexyl groups have the same spacial distance (four carbons length), the 2cyclohexylthioureido series are more active than the 2-nbutylthioureido derivatives possibly due to the increased cell membrane permeability. Further interpretation of the obtained data showed that, within the cyclohexyl series, aliphatic substitution at the 4-thiosemicarbazone moiety, such as in 44a and 44b $\left(\mathrm{Gl}_{50},(\mathrm{MG}-\mathrm{MID})=9.5\right.$ and $7.4 \mu \mathrm{M}$, respectively) increased the antitumor activity to more than threefold what was found for the aromatic substitution. our investigation revealed that the $-\mathrm{NHCOC}_{6} \mathrm{H}_{11}$ - and $-\mathrm{NHCSNHC}_{6} \mathrm{H}_{11}-$ moieties could replace each other without loss of antitumor activity, as shown from the obtained antitumor data of compounds 43b and 44b (Fig. 8) [63].

\section{Modification of 2-amine to 2-alkylamino}

The farnesylation of the cysteine residue of the C-terminal CAAX tetrapeptidic sequence of Ras protein by the zinc metalloenzyme farnesyltransferase (FTase) allows Ras to be localized. FTase inhibitors (FTis) are considered as antiproliferative and actively antineoplastics agents. The use of CAAX as a template is one of the classical approaches to the design of FTis. Valoti et al. have developed the SS stereoisomers of 2-o-tolyl substituted 4-hydroxybenzamide of methionine methyl ester, etherified at the phenolic function with pyridodioxan-2-ylmethyl, which exert a significant antiproliferative effect interfering with Ras farnesylation. Recently in a continuation of their strategy to identify new FTis and based on these preceding findings, they have considered the substitution of 3-pyridyl with other aromatic heterocycles. The 1,3-thiazole ring is a classical isostere of pyridine. 2-Aminothiazole, which is as basic as pyridine and has pronounced complexation properties towards metal ions, was selected as an interesting candidate to pyridine replacement.

Therefore, novel series of FTis by mimetics of the Cterminal CAAX tetrapeptide of Ras protein replacing cysteine with 2-amino-4-thiazolyl-, 2-mercapto-4-thiazolyl-, 2-mercapto-4-imidazolyl- and 2-methylmercapto-4-thiazolyl-acetic or propionic acid were designed. Of the four designed replacements of 3-pyridyl with new heterocycles, the compounds which have 2-amino-4-thiazolyl and a methylenecarbonylamino linker between aminothiazole and biphenyl core (45a and $\mathbf{4 5 b}$ ), exhibited a significant FTase inhibition both in vitro and in cells and reduced rat smooth muscle cell growth in the low nanomolar range. Also, in case of 45a the o-tolyl residue is determinant for the correct orientation and is itself responsible for favorable contacts within the active site, which have been imputed both to the increased hydrophobic surface area and conformational constraint. On the basis of these results, 2-aminothiazole can be considered as an alternative to heterocycles, such as pyridine and imidazole, normally used in FTase inhibitors designed as non-thiol CAAX mimetics (Fig. 9) [64, 65].

Ongoing efforts to develop new podophyllotoxin derivatives with potent biological activities led Sang et al. designed and synthesized a number of $4 \beta$-(thiazol-2-yl) amino-4'-O-demethyl-4-deoxypodophyllotoxins and were further evaluated for their effect on topo-II enzymes, H2AX phosphorylation as well as cell cycle progression. The cytotoxic effects of these compounds determined on several human cancer cell lines (A549, HepG2, HeLa, and LOVO cells) and normal cell line (WI-38). Two compounds (46a, 46b) showed greater antitumor activity and less toxicity. Compound 46a exhibited better antitumor activity on A549 $\left(\mathrm{IC}_{50}=1.3 \pm 0.9 \mu \mathrm{M}\right)$ and $\mathbf{4 6} \mathrm{b}$ also showed on A549 $\left(\mathrm{IC}_{50}\right.$ $=0.16 \pm 0.06 \mu \mathrm{M})$ and HepG2 $\left(\mathrm{IC}_{50}=0.13 \pm 0.05 \mu \mathrm{M}\right)$. Compounds 46a and 46b were the potential topo-II inhibitors (breaks double-strand DNA) and induced G2/M via the cyclin B1 and cdc2 (p34) (Fig. 9) [66].

DNA-intercalating agents are characterized by a planar chromophore, generally a tri- or tetracyclic ring system and one or two flexible basic side chains. The presence of an extra aromatic ring was proved to improve the affinity of the intercalator for the DNA molecule, consequently to a greater cytotoxic potency. Naphthalimides are the structural examples showing high antitumor activities upon a variety of murine and human tumor cells. Considering these strategies, Qian et al. designed novel naphthalimides with an extra aromatic ring fused to the naphthalimide skeletons. This aminothiazonaphthalimide family was evaluated for their in vitro antitumor activity on human lung cancer cell. Among these components, 47 indicated greater cytotoxic 


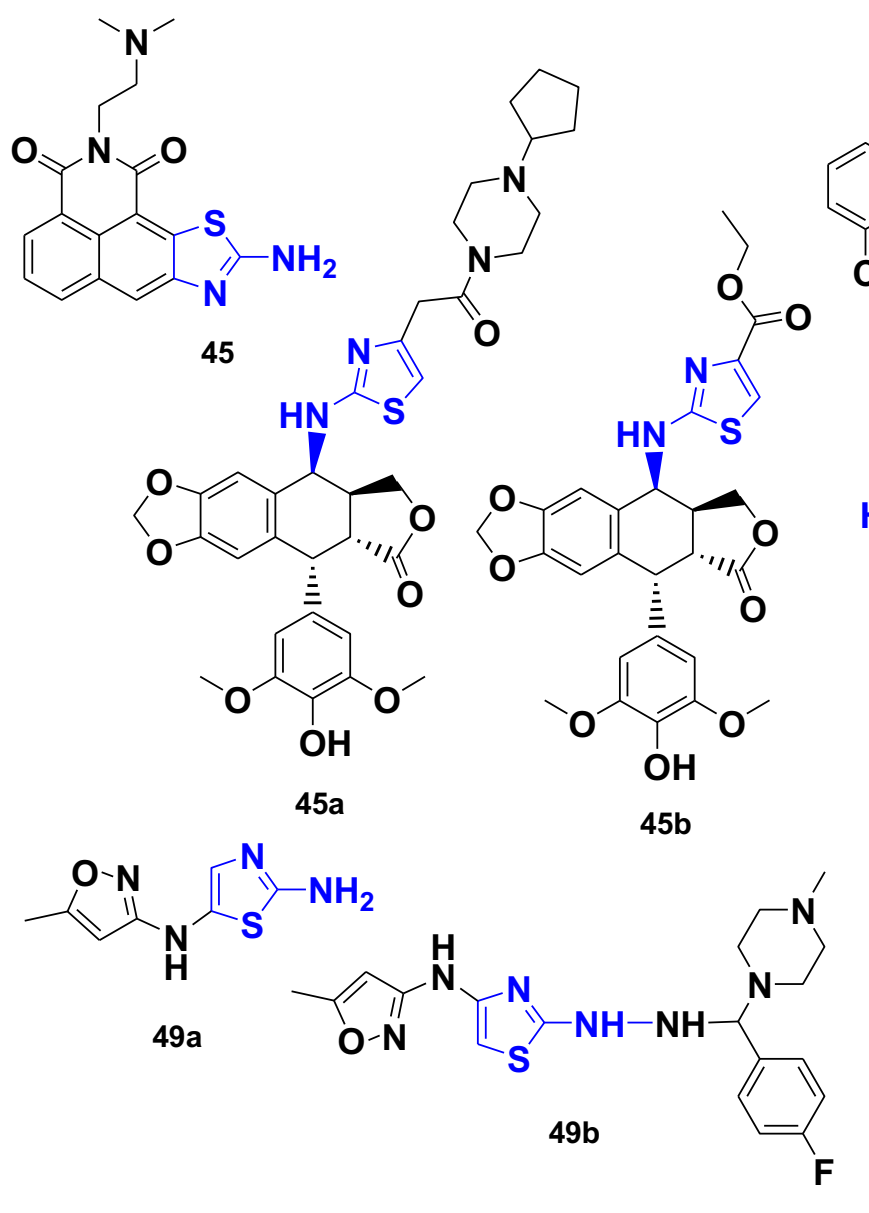<smiles>CSCCC[C@H](NC(=O)c1ccc(NC(=O)Cc2csc(N)n2)cc1-c1ccoc1)C(=O)N[C@@H](CCSC)C(=O)O</smiles><smiles>CN(C)CCN1C(=O)c2cccc3cc4nc(N)sc4c(c23)C1=O</smiles>

47

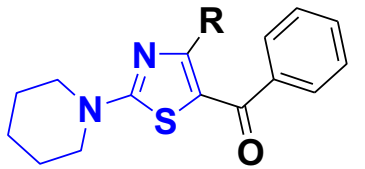

48a, $\mathrm{R}=\mathrm{Cl}$

48b, $\mathrm{R}=\mathrm{Br}$

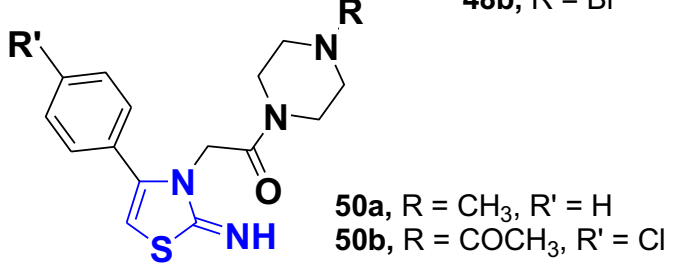

Fig. 9 2-Aminothiazole scaffold containing alkyl moiety (45-50)

effects on $\mathrm{A} 549\left(\mathrm{IC}_{50}=0.8 \mathrm{nM}\right)$ and P388 $\left(\mathrm{IC}_{50}=5 \mathrm{nM}\right)$. The probability of forming a hydrogen bond stabilized DNA-47 complex that cause efficient antitumor activity of it. This result showed that the introduction of an aminothiazole moiety to the naphthalimide skeleton resulted in higher cytotoxic potency than a thiazole, 2-chlorothiazole and 2-hydroxythiazole moiety inserted. Also, side-chain length was important in their antitumor activity. Presence of two methylene in side chain of compounds $\mathbf{4 7}$ caused more effective than other analogue that had one more methylene (Fig. 9) [67].

Alphal subunit of the $\mathrm{Na}^{+} / \mathrm{K}^{+}$-ATPase (NAK) is significantly overexpressed in gliomas, melanomas and NSCLCs and impairing its activity kills cancer cells and an efficient approach to killing MDR cancer cells. A number of thiazole derivatives including 4-halo-2,5-disubtituted-1,3thiazoles and thienothiazoles were evaluated for their in vitro growth inhibitory activity against a panel of 6 glioma cell lines. Compounds 48a and 48b exhibited $\sim 10$ times higher in vitro growth inhibition of $\alpha$ subunits of the $\mathrm{Na}^{+} / \mathrm{K}^{+}$-ATpase than perillyl alcohol $(\mathrm{POH})$, which is a NAK inhibitor. The in vitro cytostatic activities of $\mathbf{4 8 a}$ and $48 b$ were independent of the inherent resistance to pro-apoptotic stimulus related with cancer cell lines. Derivatives 48a and 48b demonstrated similar inhibition on purified guinea pig brain preparations that largely expressed subunits of NAK alpha-2 and alpha-3, while analogue $48 \mathrm{~b}$ was effective towards purified guinea pig kidney preparations that largely expressed the NAK alpha-1 subunit that was also overexpressed in gliomas, melanomas and non-small-cell lung cancers NSCLCs. The best anti-NAK inhibitors were cardiotonic steroids that showed cardiotoxicity and had very narrow therapeutic index as potent anticancer agents. Compound 48b will not probably show cardiotoxic effects. $\mathrm{POH}$ as noncardiotonic steroid-related compound demonstrated remarkable therapeutic benefits to glioma patients. $\mathrm{POH}$ created its anti-glioma activity at least partly via inhibition of both $\alpha 1$ NAK subunit and Ras oncogene. Particularly, derivative $\mathbf{4 8 b}$ was about 3 times more effective than $\mathrm{POH}$ in inhibition of $\alpha 1$ NAK subunit and was 40 times more potent than POH in inhibition of Ras (Fig. 9) [68].

Protein kinases were proved to have a significant role in anticancer drug development. One of the most essential 
kinases that play a fundamental role in signal transduction pathways is the epidermal growth factor receptor (EGFR). Consequently, inhibition of EGFR tyrosine kinase activity is of potential interest for the development of new anticancer agents.

Hopping to investigate novel 2-aminothiazole compounds incorporating different heterocycles to possess great antitumor activity, directed El-serwy et al. to synthesize a number of 4-(5-methylisoxazol-3-ylamino) thiazole derivatives and evaluate anticancer activity on HCT-116, HePG-2, and MCF-7 cell lines. Compound 49a showed the most cytotoxic effects against HePG-2 and moderate against MCF-7 cell line with $\mathrm{IC}_{50}=20.2 \mu \mathrm{g} / \mathrm{mL}$ and $\mathrm{IC}_{50}=$ $60.9 \mu \mathrm{g} / \mathrm{mL}$, respectively. Compound $49 \mathrm{~b}$ exhibited the highest antitumor activity against MCF7 cell line $\left(\mathrm{IC}_{50}=\right.$ $16.2 \mu \mathrm{g} / \mathrm{mL})$ in comparison with doxorubicin $\left(\mathrm{IC}_{50}=\right.$ $26.3 \mu \mathrm{g} / \mathrm{mL}$ ). In addition to, compound 49a inhibited EGFR, PI3K and p38 $\alpha$ kinases and identified as multitargeted. Performing the docking studies for binding modes of compound 49a investigated that in EGFR kinase, three H-bonds donors formed between $\mathrm{NH}_{2}$ linked to thiazole ring and Ala719, Leu764 and Thr766. One H-bond acceptor established between Thr766 and the nitrogen of thiazole ring and other hydrogen bond acceptor made between the nitrogen of isoxazole ring with Thr830. In P13K $\beta$ kinase, there were three hydrogen bonds between compound 49a with receptor. Two H-bonds donors formed between hydrogens of $\mathrm{NH}_{2}$ and Asp807 and Tyr833 and other Hbond was as H-bond acceptor that Tyr833 interacted with nitrogen of thiazole. Two H-bond donors established between $\mathrm{NH}_{2}$ group with Ala51 and Leu104. In addition, one $\mathrm{H}$-bond acceptor formed between nitrogen of isoxazole and Lys 53 (Fig. 9) [69].

Ali et al. were incentive for synthesizing a number of acetamide derivatives including 2-amino-4-arylthiazoles and different piperazines by the potential anticancer activity of them. Some of compounds indicated high anticancer activity in $10^{-5} \mathrm{M}$ in full of NCI 60 cell panel. In docking studies, some of them exhibited a reasonable docking score. In this study, drug likeness, drug score, ADME properties also were predicted for derivatives. Evaluation of toxicities for synthesized derivatives indicated that compounds 50a and 50b were the most active members with mean percentage growth values of 89.88 and $91.67 \%$, respectively. Compounds 50a and 50b indicated the lowest mean percentage growth over 60 cell line. Compounds 50b showed moderate activity against ovarian OVCAR-4 cancer cell line (mean percentage cell growth $=77.23 \%$ ). The presence of different substituent on phenyl ring affected on their activity, for example, introduction of chloro group in compound 50b has increased potency towards Leukemia $S R$ and MOLT-4 and the absence of substituent in phenyl ring in 50a led to increase the potency towards CNS SNB-75 and
Renal UO-31 cancer cell lines. Also, unsubstituted phenyl ring showed more enhanced potency towards both these two cell lines with cell promotion percentage of 59.05 and $72.32 \%$, respectively (Fig. 9) [70].

Several new derivatives of 2-metylamino-4-substituted1,3-thiazoles were designed and synthesized by Balanean et al. Antiproliferative activity of these compounds were evaluated in three cancer cell lines namely, Hs578T, HeLa, and HepG2. According to the in vitro assay result, compound 51a showed remarkable antiproliferative against all cell lines that $\mathrm{IC}_{50}$ values for HeLa, Hep2G and Hs578T cell lines obtained $0.823,5.077$ and $4.950 \mu \mathrm{M}$, respectively. Structure of this compound consisted of the thiazolic hydrazide-hydrazones and a chromone. Also, the excellent results of compounds 51a and 51b on the triple negative breast cancer cell line Hs578T deserved special mention. C6 substitution of 3-formylchromone caused to exhibit a better antiproliferative effects than parent compound (unsubstitution formylchromone has been the least effective compound), because enhancement of lipophilicity by methyl (51a) or chloro group increases the compound entry into the cancer cell. Replacing methyl (51a) with chlorine on $\mathrm{C}-6$ position of chromone scaffold reduced potency except for Hep2G cell lines. The $\mathrm{IC}_{50}$ values for the compound bearing thiophene moiety $(\mathbf{5 1 b})$ ranged from 7.451 to $16.439 \mu \mathrm{M}$. Thence, the better antiproliferative results in case of 51b on a more invasive breast-cancer cell line (Hs578T) could account for the two biologically active moieties acting synergistically, 2-aminothiazole core and thiophene (Fig. 10) [71].

Taking in consideration the advantage of microwave assisted synthesis in compared with conventional method like stores energy and time, minimizing thermal decomposition, and induces the yield of the synthesized compounds, Kumar et al. carried out the synthesis of a new series of 2- aminothiazole and 2- amino oxazole derivatives under microwave irradiation and evaluated for their anticancer activity. Docking study was performed for synthesized compounds to evaluate binding site of HPV 16 E2 TAD. The docking result indicated a reasonable score that showed a good activity and interaction. There were Ser 98, Glu 100, Leu 99, residues in the HPV 16 E2 TAD active site. Among these synthesized compounds, derivatives 52a and 52b exhibited a good binding score and showed significant anticancer activity on HeLa cell lines by MTT assay with $\mathrm{IC}_{50}$ values of 19.5 and $31.20 \mu \mathrm{M}$. Compound 52a exhibited the highest score $(-9.66254 \mathrm{Kcal} / \mathrm{mol})$ that it was probably the existence of a phenothiazine moiety in this compound (Fig. 10) [72].

Gorczynski et al., synthesized a series of 4-aryloxy- and 4-arylsulfanyl-phenyl-2-aminothiazoles derivatives and evaluated their cytotoxic effects on estrogen-positive (T47D, MCF7), estrogen-negative (HS-578T, MDA-MB-435, 


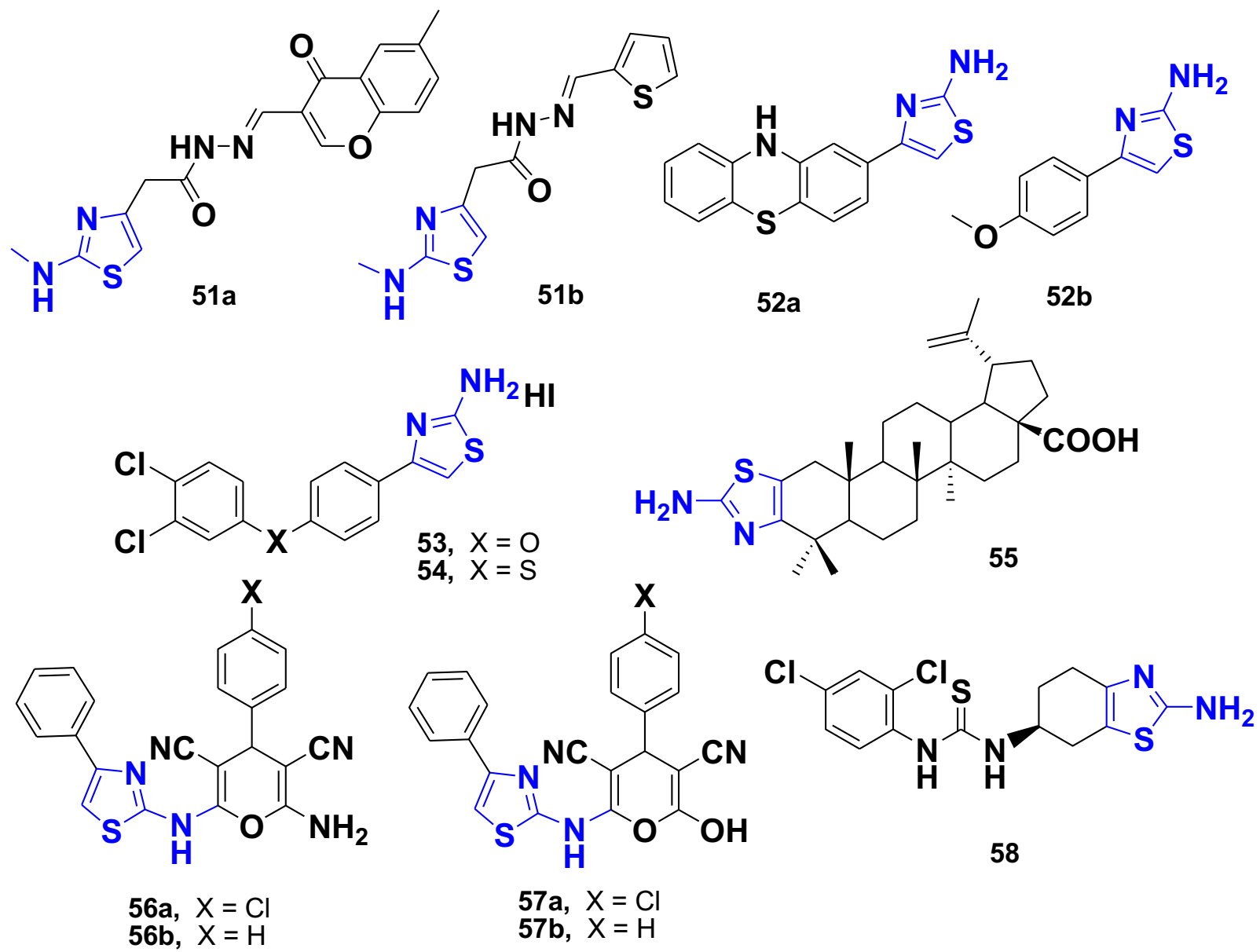

Fig. 10 2-Aminothiazole scaffold containing alkyl Moiety (51-58)

MDA-MB-231/ATCC, BT-549) and adriamycin-resistant (NCI/ADR-RES) human breast cancer cell lines. The $\mathrm{GI}_{50}$ values of these compounds defined and compared with together. The result exhibited estrogen-positive selectivity obtained by using an oxygen linkage between the two phenyl rings and estrogen-negative selectivity achieved by a sulfur linkage. Compounds with sulfur linkage showed significantly more active on different types of breast cancer cells. The most $\mathrm{GI}_{50}$ on human breast tumor cells achieved for compounds 53 and 54. These compounds with 3,4dichloro substitutions exhibited selectivity for the adriamycin-resistant cell line. The presence of para-chloro on phenyl ring was more active than the para-methyl. Compounds 53 and 54 recognized as promising compounds for future mechanistic studies (Fig. 10) [73].

A number of aminothiazoles derivatives were prepared and assessed against eight cancer cells and two non-cancer fibroblasts. Some of compounds exhibited the $\mathrm{IC}_{50}$ value below $5 \mu \mathrm{M}$ in CCRF-CEM cells. Compound $\mathbf{5 5}$ was identified as the best candidate for new anticancer drug exploration with therapeutic index $>21$. Its cytotoxicity on both fibroblasts was higher than $50 \mu \mathrm{M}$ resulting in interesting therapeutic index values. This derivative with the free amino and the free C-28 carboxylic units exhibited $\mathrm{IC}_{50}=2.4 \mu \mathrm{M}$ against CCRF-CEM cells. More importantly, aminothiazoles containing unsubstituted amino moiety $\mathbf{5 5}$ (derivatives of betulonic acid) had better activity in CCRFCEM cell line than most of the aminothiazoles containing the substituted amino group. It was demonstrated quite a high stability in human plasma (after incubation for $2 \mathrm{~h}$, $85-100 \%$ of the original quantity of substance is remaining). Microsomal stability was the main mechanism of plasma clearance and showed sufficient stability in hepatic microsomes with low or medium category of intrinsic clearance. Compounds $\mathbf{5 5}$ proved the strongest apoptotic activity. Protein expression analysis showed caspase 3 and 7 activation, as well as PARP cleavage in cells treated by $\mathbf{5 5}$ (Fig. 10) [74].

Hamed et al. described synthesis and antitumor activity of 2-Amino-4-phenylthiazole analogs which were used for a series of heterocyclization reaction to produce pyran, pyridine and thiazole derivatives. Antitumor activity of these derivatives was measured on six cancer cell lines namely NUGC, HR, DLD1, HA22T, HEPG2, MCF, HONE1 and 
WI38 (normal fibroblast cells). The multicomponent reactions of 2-Cyano-N-(4-phenylthiazol-2-yl)acetamide with any of the aromatic aldehydes and malononitrile gave the pyran derivatives. According to the cytotoxicity studied, compound 56a showed the excellent activity in these derivatives. IC $_{50}$ values for NUGC, DLD1, HA22T, HEPG2, MCF, HONE1 obtained 22, 39, 160, 82, 122, $49 \mathrm{nM,}$ respectively. However compound $\mathbf{5 6} \mathbf{b}$ showed high potency against NUGC, DLDI, HA22T, HEPG2and HONE1 cell lines and low potency against MCF cell lines. Between the other pyran derivatives which were synthesized from 2cyano-N-(4-phenylthiazol-2-yl)acetamide with any of benzaldehydes and ethyl cyanoacetate, compound 57b showed high potency against DLDI, HEPG2 and MCF cell lines with $\mathrm{IC}_{50}$ 's 368,224 and $310 \mathrm{nM}$ and 57a showed high potency against HONE1 cell line with $\mathrm{IC}_{50}$ value of $666 \mathrm{nM}$. Also, they prepared N-phenylthiourea, N-cyanoacetyl, arylidene, aryl hydrazone, and pyrimidine derivatives, but were exhibited moderate activity (Fig. 10) [75].

A novel series of (S)-2,6-diamino-4,5,6,7-tetrahydrobenzo[d]thiazole derivatives were designed and synthesized by Prasanna and coworkers. These compounds were evaluated on K562 and Reh by trypan blue exclusion, MTT, LDH assays as potential antileukemic agents. The results displayed that thiazole derivatives with electron withdrawing halogen groups at phenyl ring of arylthiourea increased cytotoxic effect. The presence of chloro and fluoro in phenyl ring exhibited high potency compared with compounds without them. The best result obtained for compound $\mathbf{5 8}$ with 2,4 dichloro groups. IC $_{50}$ value for $\mathbf{5 8}$ were 11 and $20 \mu \mathrm{M}$ for K562 and Reh cell lines, respectively. According to the flow cytometric analysis by annexin V-FITC/ propidium iodide (PI) double staining and DNA fragmentation, compound $\mathbf{5 8}$ showed apoptosis inducer effect in cancer cell line tested (Fig. 10) [76].

Considering Combretastatin A-4 (CA-4) (59) as one of the well-known natural molecules that inhibits cell growth at nanomolar concentrations, exhibiting inhibitory effects even on multidrug-resistant cancer cell lines through its interaction with tubulin at the colchicine site. Structure-activity relationship (SAR) studies of CA-4 have underlined that the presence of the 3,4,5-trimethoxy substituted A-ring and the 4-methoxy substituted B-ring separated by a double-bond with cis-configuration are fundamental for optimal antiproliferative activity. It has also been reported that 3-hydroxy group on the B-ring is not necessary for potent activity. These histories caused Romagnoli and coworkers to synthesize a novel series of 2amino-4-(3',4',5'-trimethoxyphenyl)-5-aryl thiazoles with the goal of evaluating the effects of substituents on the phenyl at the 5-position of the thiazole skeleton on biological activities. On the basis of in vitro antiproliferative activity data, the best substituents for the C5-position of the thiazole ring were revealed (60a-e). An ethoxy group at the para-position (60e) produced the most active compound in the series, with $\mathrm{IC}_{50}$ values of $0.03-0.9 \mathrm{nM}$ against five of seven cancer cell lines. The most active compounds retained full activity in multidrug-resistant cancer cells and acted through the colchicine site of tubulin. Treated cells were arrested in the G2/M phase of the cell cycle, with cell death proceeding through an apoptotic pathway that was only partially caspase-dependent (Fig. 11) [77].

In a similar study close to the latter work and taking into consideration above results, Romagnoli et al. have synthesized a new series of 2-substituted-4-(3,4,5-trimethoxyphenyl)-5-aryl thiazoles, all of which retain at the $\mathrm{C} 4$ - and C5-positions of the thiazole ring the same substituents as derivatives 60a-e, examining the effect on biological activity derived by replacement of the amino group at the C2-position of the thiazole nucleus with different moieties, such as $\mathrm{N}$-methylamine, N,N-dimethylamine and methyl. The potency at the 2-position increased as follows: $\mathrm{NHCH}_{3}$ $>\mathrm{CH}_{3} \gg \mathrm{N}\left(\mathrm{CH}_{3}\right)_{2}$. Presence of N-methylamino at the 2position of thiazole remarkably improved antiproliferative effects against MCF-7 cells with respect to C2-amino counterparts and $\mathrm{N}, \mathrm{N}$-dimethylamino decrease 1-2 log in activity. The $2 \mathrm{~N}$-methylamino thiazole derivatives 61a-c were the most active compounds as antiproliferative agents, with $\mathrm{IC}_{50}$ values from low micromolar to single-digit nanomolar. Among these synthesized compounds, derivative 61c showed more potency. These compounds also showed activity on multidrug-resistant cell lines overexpressing P-glycoprotein. The compounds interacted with colchicines site of tubulin polymerization and interference with microtubule probably exhibited antiproliferative effect. Its $\mathrm{IC}_{50}$ value for inhibiting tubulin polymerization was $0.89 \mu \mathrm{M}$ and the percentage of colchicine binding inhibition yielded $83 \%$. Compound $61 \mathrm{c}$ using the activation of caspase 2,3 , and 8 induced apoptosis and did not made mitochondrial apoptotic pathway (Fig. 11) [78].

Considering chalcones as an important subgroup of flavonoids and particularly one of the desirable scaffolds displaying unique anticancer activities, in a study by Ayati et al. a number of 4-amino-5-cinnamoylthiazoles derivatives were synthesized and investigated as chalcone- like anticancer agents. Synthesized derivatives were classified to three groups; pyrrolidine, piperidine, morpholine, and tested for their antiproliferative activities on MCF-7, HepG2 and SW480. In SAR studies, presence of various cyclic amine stocks to the thiazole core and substituent on the phenyl were assessed for antiproliferative profile. As a result, more favorable ring for antiproliferative activity was pyrrolidine ring. Pyrrolidine derivative namely $(E)-1$-(4-amino-2(pyrrolidin-1-yl)thiazol-5-yl)-3-(2,4-dichlorophenyl)prop-2-en1-one (62) could significantly prevent proliferation of MCF7 and especially $\mathrm{HepG} 2$ cell lines with $\mathrm{IC}_{50}=12.6$ and 


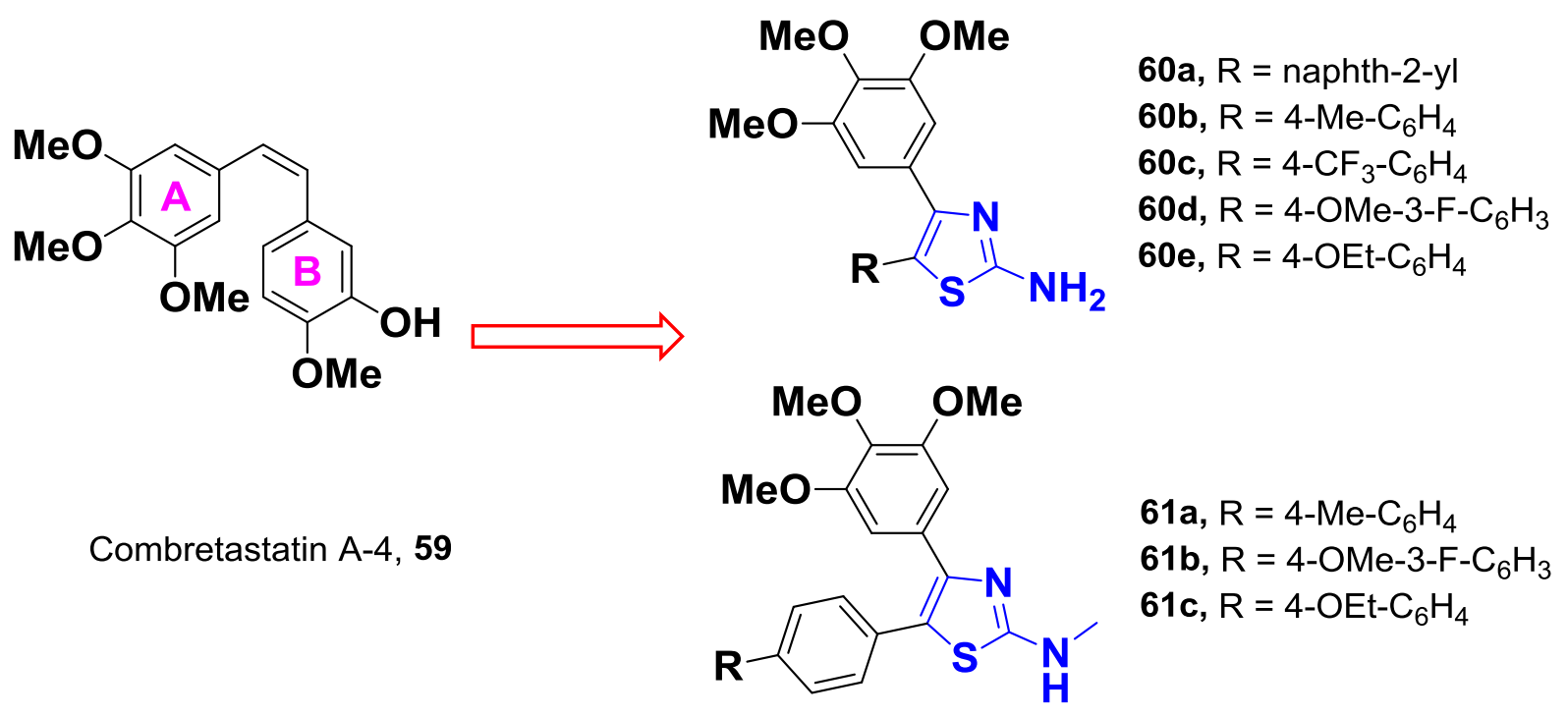

Fig. 11 Design 2-aminothiazoles as microtubule targeting agents based on combretastatin

$10.6 \mu \mathrm{g} / \mathrm{mL}$, respectively. This compound was twofold more potent than its corresponding piperidine analog and was found to be significantly more active than its morpholine congener. While the unsubstituted cinnamoyl compounds in all series were active against all tested cell lines, introduction of 2,4-dichloro substituent on phenyl ring in pyrrolidine series increased the cytotoxicity. For comparison of 2,4-dichloro derivatives, 62 with the corresponding 4-chloro analog, incorporation of second chlorine on phenyl ring increased cytotoxic effect on cell lines in pyrrolidine and morpholine series. Compound 62 blocked G2 phase of cell cycle and induced apoptosis pathway that led to inhibit proliferation of HepG2 cells. Percentage of apoptotic cells for compound $\mathbf{6 2}$ was obtained $44.3 \%$ that was higher than etoposide $(18.1 \%)$. These results indicated that thiazole-based chalcones could be considered as effective cytotoxic leads (Fig. 12) [79].

Due to importance of chalcone type compounds in the last study by Ayati et al. and according to above findings and in continuation of their studies on the synthesis of chromene-based anticancer agents, this research group has described coumarin-containing hybrid compounds namely 3-(4-amino-2-(cyclic amino-1-yl)thiazole-5carbonyl)-2Hchromen-2-ones and 3-(4-amino-2-(arylamino)thiazole-5carbonyl)-2H-chromen-2-ones as new anticancer agents. $\mathrm{IC}_{50}$ values for antiproliferative activity of synthesized compounds were investigated against breast carcinoma (MCF-7), human colon adenocarcinoma (SW480), and human liver cancer (HepG2) cell lines using MTT assay. Also, the effect of arylamino and different cyclic amino groups at C-2 of thiazole core was investigated. Particularly, thiomorpholine derivative (63) with $\mathrm{IC}_{50}$ values of 7.5 and $13.0 \mathrm{mg} / \mathrm{ml}$ found to be the most potent compound against
MCF-7 and SW480 cells, respectively. Moreover, the structure-activity relationship studies revealed that 2-(cyclic amino) derivatives exhibited better cytotoxic effects rather than 2-arylamino analogs. Between the cyclic amine derivatives, six-membered analogs were more potent than fivemembered cyclic amine congener against MCF-7 and HepG2 cells. Replacement of oxygen in morpholine derivative by sulfur resulted in compound $\mathbf{6 3}$ with greater potency against all tested cell lines. Further investigation by flow cytometric analysis confirmed that compound $\mathbf{6 3}$ induces apoptotic cell death in MCF-7 cells and cause G1phase arrest in the cell cycle (Fig. 12) [80].

The research group of Ding synthesized a new series of nitrogen-enriched oridonin analogues with thiazole-fused A-Ring. Oridonin (64) is a natural compound that extracted from Isodon rubescens and exhibited a moderate anticancer activity. This natural compound has poor oral bioavailability and determinate aqueous solubility. To fix these defects, designed and synthesized derivatives with thiazole ring fused A-ring. In SAR studies, insertion of 2aminothiazole at $\mathrm{C} 1-\mathrm{C} 2$ position of oridonin A-ring led to improvement of defects. $\mathrm{N}$-alkylation of 2-amino thiazole increased potency on breast cancer cells. Compound $\mathbf{6 5}$ with $\mathrm{N}$-allyl substituent was more potent than other derivatives. In biological evaluation, some of derivatives showed potential antiproliferative activity on breast, pancreatic, and prostate cancer, whereas their aqueous solubility increased. Among these compounds, compound $\mathbf{6 5}$ displayed the highest antiproliferative effect on MCF-7 and MDA-MB-231 cells and remarkably induced apoptosis at MDA-MB-231 and MCF-7/ADR cells. The function of compound $65(0.25-1.0 \mu \mathrm{M})$ on MDA-MB-231 cells indicated the down-regulation of $\mathrm{Bcl}-2$ protein, the upregulation 


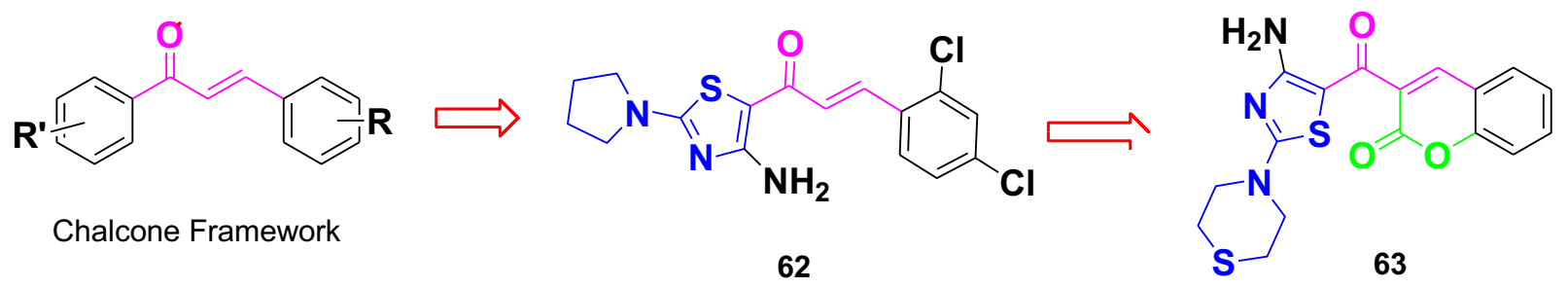

Fig. 12 Design 2-aminothiazoles as chalcone-like anticancer agents

Fig. 13 Oridonin analogues with 2-aminothiazole-fused A-ring

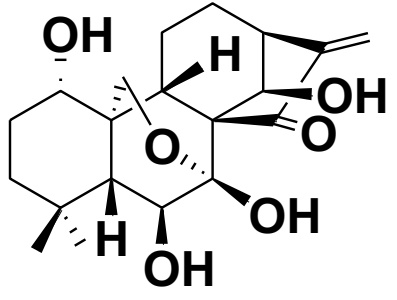

Oridonin, 64

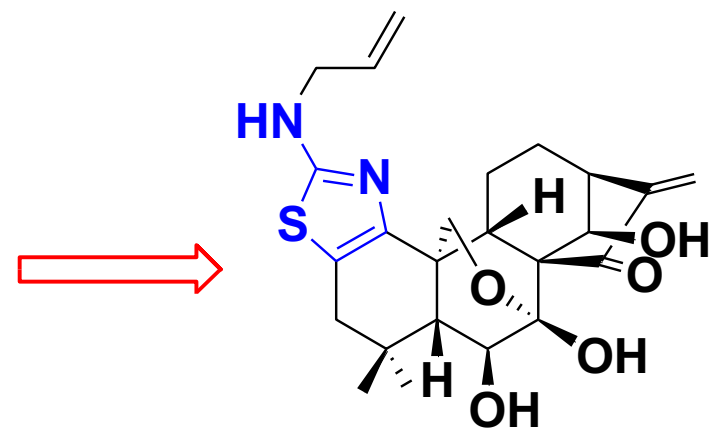

65 of Bax protein and also decreasing expression of NF- $\mathrm{KB}$ (p65) protein. According to the in vivo assay, compound $\mathbf{6 5}$ $(5 \mathrm{mg} / \mathrm{kg})$ remarkably inhibited MDA-MB-231 xenograft tumor growth and showed better aqueous solubility than oridonin. Compound 65 (CYD0618) with excellent aqueous solubility was an antitumor drug candidate (Fig. 13) [81].

\section{Modification of 2-amine to 2-arylamino}

Considering Sphingosine kinases (SphK1, SphK2) as main regulators of sphingosine-1-phosphate (S1P), an aminothiazole class of Sphingosine kinases inhibitors were designed, synthesized, and evaluated by Vogt et al. Modifications of the known SKI-II (66) scaffold for definition of structureactivity relationships discovered potent inhibitors. The hydroxy group in 4-position of the phenyl ring seems to be crucial for inhibitory potential, because of shift it to the 2and 3-position led to loss of inhibition and insertion of a methylene spacer between hydroxyl moiety and aromatic ring produced an inactive compound. Interestingly, the methoxygroup in 2-position of the phenyl ring showed a slight tendency towards SphK1-selective inhibition. Analogues containing alkyloxy-substituents in 4- and 3-position as dimethoxy lost their ability to inhibit SphKs. But by introducing a third methoxy group in 5-position a substantial increase in potency and isoenzyme preference could be achieved. Therefore, presence of 3,4,5-trimethoxyphenyl was a favorable substitution for inhibitory activity. Compounds 68 (ST-1780) and 69 (ST-1577) were candidated for structural modifications and in vivo investigation as selective SphK1 and SphK2 inhibitors, respectively. Compound $\mathbf{6 7}$ (ST-1803) exhibited the most promising inhibition of over $50 \%$ with $\mathrm{IC}_{50}$ values of 7.3 and $6.5 \mu \mathrm{M}$ towards SphK1 and SphK2, respectively. Derivative $\mathbf{6 7}$ have not exhibited apparent cytotoxicity. These desirable properties were qualified compound $\mathbf{6 7}$ for further physicochemical studies (Fig. 14) [82].

Recently, Traf2- and Nck-interacting kinase (TNIK) has been proposed as a first-in-class anti-cancer target molecule to regulate Wnt signaling pathway. Yamada et al. have designed and synthesized a novel aminothiazole inhibitor of TNIK, 5-(4-methylbenzamido)-2-(phenylamino)thiazole-4carboxamide (KY-05009 (3)). It was shown to be a potent inhibitor of TNIK attenuating $\beta$-catenin/TCF4-mediated transcription and MLK1 with $\mathrm{IC}_{50}$ values of 9 and $18 \mathrm{nM}$ in a kinase assay). Also, in A549 cells its efficacy to inhibit EMT in cancer cells was validated through MAP kinases (ERK and JNK) signaling pathways. The molecular docking/binding report revealed that KY-05009 has two H-bond interactions with Cys108 in the hinge region of TNIK, and $\mathrm{CH} / \pi$ interactions with Val31, Gly111, and Leu160 [83].

In a study by Wan and coworkers, a new thiazole derivative (4-tert-butyl- $N$-(2-fluorophenyl)-5-(1H-1,2,4-triazol1-yl)thiazol-2-amine) was synthesized and performed X-ray structure via single-crystal X-ray diffraction. In X-ray analysis, the typical V-type intramolecular hydrogen bond between the amino and triazole groups played a valuable role in stabilizing the compound crystal structure. The 
<smiles>Oc1ccc(Nc2nc(-c3ccc(Cl)cc3)cs2)cc1</smiles>

66

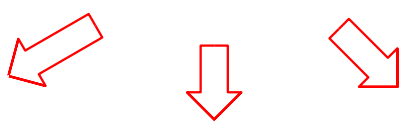

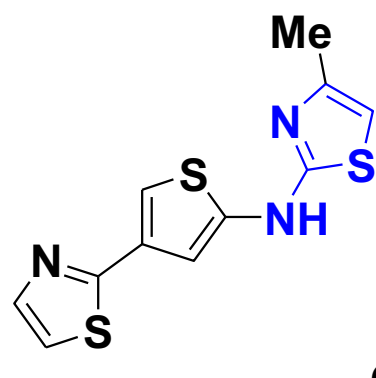

67<smiles>CO/C=C/CNc1nc(-c2ccc(Cl)cc2)cs1</smiles>

68

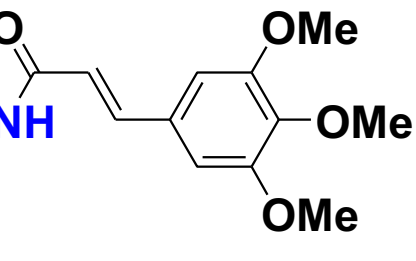

69

Fig. 14 Modifications of the known SKI-II scaffold to an aminothiazole class of SphK inhibitors

phenyl, thiazole, and trazolyl rings organized the three planes of the compound 70. Biological assessment was performed by MTT method. Compound $\mathbf{7 0}$ exhibited potential antitumor activity and $\mathrm{IC}_{50}$ value obtained $0.122 \mu \mathrm{mol} / \mathrm{ml}$ on Hela cells (Fig. 15) [84].

Sphingosine kinases (SphKs) play an important role in the production of sphingosine-1-phosphate (S1P). For blocking SphK dependent angiogenesis probably needed inhibition of both isoforms of SphK. Gustin et al., identified a new series of SphK inhibitors by structure-based approach. New synthesized compounds can be inhibited both isoforms of SphK (SphK1/SphK2) and specificSphK1. Human SphK1/2 biochemical assay and WM266-4 cell assay was performed for synthesized compounds. The activity of compound 71a and 71b was determined against SphK1, SphK2 with $\mathrm{IC}_{50}=0.02,0.1 \mu \mathrm{M}$ for 71a and $\mathrm{IC}_{50}=0.003,0.04 \mu \mathrm{M}$ for 71b and against WM266-4 cell $\left(\mathrm{EC}_{50}=0.09 \mu \mathrm{M}\right.$ for 71a and $\mathrm{EC}_{50}=0.36 \mu \mathrm{M}$ for 71b). Then, in biochemical assays, compound $\mathbf{7 1 b}$ showed more potent than 71a. Pharmacokinetic parameters were evaluated for both compounds in rat, for example, moderate clearance obtained for them. Compound 71a exhibited reasonable bioavailability in mice and with having good pharmacokinetic properties, showed high selectivity against SphKs. In compound 71a, $\mathrm{IC}_{50}$ values for murine $\mathrm{SphK}$ and murine SphK2 obtained 0.07 and $>10 \mu \mathrm{M}$ and in compound 71b, $\mathrm{IC}_{50}$ values determined 0.02 and $>10 \mu \mathrm{M}$. The pharmacodynamic assay was also assessed for compound 71a and investigated the circulating levels of S1P and levels of 71a in plasma. According to the SAR studies, (2 R, 4 S)-2(hydroxymethyl) piperidin-4-ol moiety as a critical structure formed hydrogen bonds with Asp81 and Asp178. A hydrogen bond made between the oxygen of the piperidine hydroxymethyl and the carboxyl of Asp178 and the oxygen of the 4-hydroxy piperidine and the carboxyl of Asp81 interacted with together by H-binding. A polar pocket including Asp81 and Asp178 filled using the piperidine. An excess methyl group in the 4- position of the piperidine reduced about tenfold potency. Two chlorine atoms on phenyl group were set in a hydrophobic pocket. The van der Waals interaction was made between the meta-chlorine and Met306, Leu261, and Leu268. The para-chlorine seen to form van der Waals interactions with Phe288, His311, and Leu319 (Fig. 15) [85].

To date, few examples of selective SphK2 inhibitors or dual SphK1/SphK2 inhibitors have been reported. Therefore, in a similar study and in related to the previous work, Rex and coworkers, designed and synthesized the potent SphK1/2 inhibitors $\mathbf{7 2}$ by using structure-guided design approach. Production of intracellular S1P in human cells 
<smiles>CC(C)(C)c1nc(Nc2ccccc2F)sc1-n1cncn1</smiles>

70<smiles>OCC1CC(O)CCN1Cc1ccccc1</smiles><smiles>OC[C@@H]1CC(O)CN1CCCc1ccc(Nc2nc(-c3cccc(C(F)(F)F)c3)cs2)cc1</smiles>

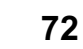<smiles>c1ccccc1</smiles><smiles>C</smiles><smiles>[AlH2]</smiles><smiles>Cc1ccc(-c2csc(Nc3ccc(O)cc3)n2)cc1</smiles><smiles>[R]c1nc(-c2cccc(I)c2)cs1</smiles>

$74 a, R^{\prime}=O M e$ 74b, R'= $\mathrm{NHCOCH}_{3}$<smiles>[R]O[NH+]([O-])c1ccc(Nc2nc(N)c(C(=O)c3ccccc3[N+](N)=O)s2)cc1</smiles>

75

Fig. 15 2-Aminothiazole scaffold containing aryl Moiety (70-75)

and extenuation of vascular permeability in mice were inhibited by synthesized compound but this compound did not decreased tumor cell viability in vitro and in vivo. Determination of human and murine SphK activity was performed in biochemical assays for compound 72. $\mathrm{IC}_{50}$ values of compound $\mathbf{7 2}$ for hSphK1, hSphK2, mSphK1 and mSphK2 gained $0.008,0.060,0.055$, and $>5 \mu \mathrm{M}$. This compound was inhibited human SphK1, SphK2, and murine SphK1 but displayed a lake of inhibition in murine SphK2. Compound $\mathbf{7 2}$ in concentrations less than one micromolar, thoroughly inhibited S1P formation in tumor cells. In $72 \mathrm{~h}$ proliferation assays with the same concentration, mentioned compounds did not exhibit effect on viability in a panel with ten tumor cell lines. At concentrations 3 to $30 \mu \mathrm{M}$ were observed cell death that was probably created by physicochemical properties of this compound. Evaluation of siRNA experiments for SphK1/2 in different cell lines failed to display any statistically remarkable effects on tumor cell viability. As a result, the SphK rheostat do not lead to an important effect on cell viability (Fig. 15) [86].

Regarding in demonstrated impressive anticancer activity of SK1 and SK2, Compound $\mathbf{7 3}$ was identified by Smith and co-workers from a high throughput screen. 4-((4-(4Chlorophenyl)thiazol-2yl)amino)phenol (73) exhibited some selectivity toward SK2 as a kinase inhibitor (Ki: $\mathrm{SK} 2=7.9 \mu \mathrm{M}, \quad \mathrm{SK} 1=16 \mu \mathrm{M})$ but is a more powerful promoter of SK1-degradation (100\% SK1 ablation at $10 \mu \mathrm{M})$ and has been identified as an inhibitor of Des1 activity $(\mathrm{Ki}=0.3 \mu \mathrm{M})$. Presumably, the exchange of the thiazole ring in $\mathbf{7 3}$ with the oxadiazole ring has decreased affinity for the allosteric site and increased affinity for either the ATP or Sph binding sites on SK1 and SK2 (Fig. 15) $[87,88]$.

A number of thiazole derivatives were synthesized and their cytotoxicity was assessed on 66 human tumor cell lines from different neoplastic diseases. The preliminary anticancer test was performed for selected compounds on BC, NSCLC, and CNSC cells and the test results gained as growth percent value. According to the results of preliminary anticancer test, six compounds selected for second step of evaluation. The test results obtained as $\log _{10} \mathrm{GI}_{50}$ (growth inhibition of $50 \%$ ). Compounds with $\log _{10} \mathrm{GI}_{50}$ more than -4 were posed inactive. All of tested compounds exhibited $\log _{10} \mathrm{GI}_{50}$ greater than -4 , therefore they have a significant activity against cancer cells. The mean graph midpoint (MG-MID) values for standard compounds of melphalan and cis-diaminodichloroplatinum obtained -5.09 and -6.20 . In comparison of the mean graph midpoint (MG-MID) value for melphalan $(-5.09)$ and cis-diaminodichloroplatinum $(-6.20)$ as standards and tested compounds, it can be concluded that tested compounds created high potency. Compound 74a with MG-MID $=-6.02$ was almost equal to the standard compound of cis-diaminodichloroplatinum. Also, the activity 
values of 74a and 74b are higher than that of the other control compound melphalan. Derivative $\mathbf{7 4 b}$ was the most active compound against colon cancer $\left(\log _{10} \mathrm{GI}_{50}=-6.64\right)$, that was more than cis-diaminodichloroplatinum (Fig. 15) [89].

Cyclin-dependent kinases (CDKs) are family of serine/ threonine kinases those are play a key role in progression and transcription of cell cycle. Schonbrunn et al., designed and developed new and highly potent diaminothiazole inhibitors of $\mathrm{CDK} 2\left(\mathrm{IC}_{50}=0.0009-0.0015 \mu \mathrm{M}\right)$ from a single HTS hit compound with weak inhibitory activity $\left(\mathrm{IC}_{50}=15 \mu \mathrm{M}\right)$. Structure-based design using 35 highresolution cocrystal structures of CDK2 was performed for different analogues of the hit compound. Investigation of compound $\mathbf{7 5}$ against 339 kinases indicated great selectivity for CDKs. This compound remarkably suppressed proliferation of cancer cell lines which there was a correlation between the inhibition of Rb-phosphorylation and apoptosis onset. According to the results, the potential of this new synthesized inhibitors exhibited better development into CDK-particular chemical probes or therapeutics. In the SAR studies, $\mathrm{R}_{2}$ substitution with meta-pyridine showed the more potent than the based compound and in ortho- or para-pyridine showed the less potency than the based compound. Replacing of phenyl and cyclohexyl at $\mathrm{R}_{1}$ resulted increasing of activity over the parent compound. Insertion of sulfonamide group at the para-position of the phenyl ring $\left(\mathrm{R}_{1}\right)$ resulted remarkable activity over the parent compound that was attributed formation of hydrogen bonding interaction between the sulfonamide unit and amino acids His84, Gln85, Asp86, and Lys89. Insertion of sulfonamide group at the meta-position of the phenyl ring $\left(\mathrm{R}_{1}\right)$ led to loss of activity. Compound $\mathbf{7 5}$ inhibited CDK2cyclin A2 $\left(\mathrm{IC}_{50}=1.5 \mathrm{nM}\right)$ using the P33-radiolabeled assay. In compound $\mathbf{7 5}$, the nitro group at ortho-position of phenyl ring was nested in a hydrophobic pocket with Val18, Ala31, Lys33, and Phe80 (Fig. 15) [90].

The research group of Shi, synthesized a number of thiazolyl-chalcones (E)-1-(4-methyl-2-arylaminothiazol-5yl)-3-arylprop-2-en-1-ones and assessed activity of these compounds against different cancer cell lines BGC-823, PC3, NCI-H460, BEL-7402 by MTT assay. Some compounds indicated activity on cancer cells with $\mathrm{IC}_{50}$ value below $10 \mu \mathrm{M}$. According to the in vivo test against S180 xenograft in mice, compounds $\mathbf{7 6} \mathbf{a}$ and $\mathbf{7 6} \mathbf{b}$ showed moderate activity that inhibited tumor weight $22-25 \%$. Based on results, compound 76b indicated good anticancer activity, in vitro and in vivo. Presence of thiazole groups into chalcones can improve anticancer activity of them (Fig. 16) [91].

Founding the ability of certain 2-aminothiazole derivatives to inhibit cyclin-dependent kinases, has intrigued Stieber and coworkers to employ a new and effective method for the solid-phase synthesis of 2-aminothiazole derivatives and also evaluated the biological activity of the library. Biological activity of these compounds was investigated against the cyclin-dependent kinases and receptor tyrosine kinase. None of the compounds showed appreciable inhibitory activity against CDK-2 and CDK-4. However, Compound 77a displayed activity against VEGFR-2, Tie-2, and FGFR-1 with $\mathrm{IC}_{50}$ below $10 \mu \mathrm{M}$. Compound 77b exhibited antitumor activity against Tie-2 $\left(\mathrm{IC}_{50}=4.8 \mu \mathrm{M}\right)$ and VEGFR-2 $\left(\mathrm{IC}_{50}=31 \mu \mathrm{M}\right)$. Based on this finding, there are possibilities for receptor tyrosine kinase inhibition with dual selectivity for Tie-2 and VEGFR-2 and the development of novel antitumor agents (Fig. 16) [92].

Sun and coworkers designed and synthesized a new series of N,4-diaryl-1,3-thiazole-2-amines that investigated as tubulin inhibitors. Evaluation of target compounds for their antiproliferative activity was performed against three human cancer cell lines namely, gastric adenocarcinoma (SGC-7901), lung adenocarcinoma (A549), and fibrosarcoma (HT-1080). Most of compounds exhibited moderate activity in the $\mu \mathrm{M}$ range. Among these compounds, compound 78 was identified as the most potent compound. $\mathrm{N}$-(2,4-dimethoxyphenyl)-4-(4-methoxyphenyl)-1,3-thiazol-2-amine (78) potently caused inhibition of tubulin polymerization with $\mathrm{IC}_{50}$ values between 0.36 and $0.86 \mu \mathrm{M}$ in the three cancer cell lines and disruption of tubulin microtubule dynamics in a manner similar to CA-4. Induction of SGC-7901 cell cycle arrest was occurred at the $\mathrm{G}_{2} / \mathrm{M}$ phase in both concentration and time-dependent manners using compound 78. The 2,4-dimethoxy substitutions of $\mathrm{A}$ ring in the amino-linked compounds displayed the most remarkable antiproliferative activity. Presence of a methyl or acetyl group at the $\mathrm{N}$ linker position of the 2aminothiazole scaffold caused reduction of activity compared to compound 78. Hydrophobic interactions were formed between compound $\mathbf{7 8}$ and some amino acids of $\beta$-tubulin. A hydrogen bonding was created between the thiol of Cys $\beta 241$ and the nitrogen of the amino linker and other hydrogen bonding was formed between the oxygen of methoxy group in ring A of compound $\mathbf{7 8}$ and the hydroxyl group of Thr $\alpha 179$. According to the docking results, this compound could bind to the binding site of colchicine in tubulin (Fig. 16) [93].

In regard enriching biologically relevant chemical space (BRCS) around the 2-aminothiazole core, Titus et al. designed the next higher homolog of 2,4-diamino-5-ketothiazoles by providing an azomethine linkage at $\mathrm{C} 4$ which resulted in 2-amino-4-alkylidene/arylidenehydrazino-5benzoyl-1,3-thiazoles (HAT). The HATs were synthesized by $[4+1]$ ring closure between a $\mathrm{C}-\mathrm{N}-\mathrm{C}-\mathrm{S}$ fragment aminoamidinothiourea (AATU) and $\alpha$-halo ketone. Incorporation of azomethine on $\mathrm{C} 4$ hydrazine was performed by isobutyl, cyclohexyl, and benzyl groups that resulted IBHATs (79a), CyHATs (79b), and BzHATs (79c), respectively. In molecular docking, the virtual screening in 
<smiles>COc1cc(/C=C/C(=O)c2sc(Nc3c#[R]ccc3)nc2C)cc(OC)c1OC</smiles>

76a, $\mathrm{R}=3,4-\mathrm{Cl}$

$76 \mathrm{~b}, \mathrm{R}=3-\mathrm{Cl}, 4-\mathrm{F}$<smiles>[R3]CCCCCC(=O)c1sc(Nc2ccc(OC)cc2)nc1NN=C(C)CC</smiles>

$79 a$<smiles>[R]NS(=O)(=O)c1ccc(Nc2ncc(C(C)C)s2)cc1</smiles>

80<smiles>O=C(O)c1ccc(Nc2nc(-c3ccc4ccccc4c3)cs2)cc1O</smiles>

83<smiles>COc1ccc(Nc2nc(NN=C3CCCCC3)c(C(=O)c3ccccc3)s2)cc1</smiles>

$79 b$<smiles>Cc1ccc(Nc2nc(-c3cccc(Br)c3)cs2)cc1</smiles>

$\mathrm{COOH}$

77a, $\mathrm{R}=\mathrm{Ph}, \mathrm{R}^{\prime}=\mathrm{H}, \mathrm{R}^{\prime \prime}=$ furan

77b, R = H, R' = 4-Cl, R" = 4-bromoPh<smiles>N/N=C\c1ccccc1</smiles>

78<smiles>COc1ccc(-c2csc(Nc3ccc(OC)cc3OC)n2)cc1</smiles><smiles>COc1ccc(Nc2nc(N)c(C(=O)c3ccccc3)s2)cc1</smiles><smiles>[R]c1ccc(Nc2nc([R])cs2)cc1</smiles>

81

$\mathbf{R}_{\mathbf{1}}=\mathrm{Ph}, m$-nitroPh, $m$-bromoPh, $m$-methoxy $\mathrm{Ph}$

$\mathbf{R}_{\mathbf{2}}=m-\mathrm{COOH}, p-\mathrm{COOH}, p-\mathrm{CO}_{2} \mathrm{Me}$

82

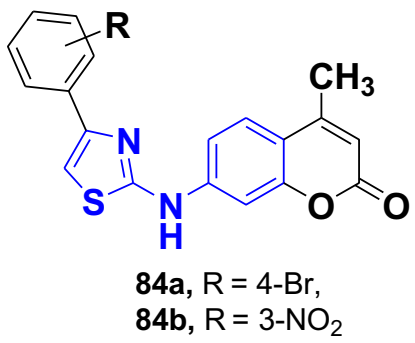

Fig. 16 2-Aminothiazole scaffold containing aryl moiety (76- 84)

three classes of anticancer target proteins containing estrogen receptor (3ERT), cyclin dependent kinase (3FDN), and Aurora kinase (3LAU) recognized selective binding of the designed compounds as ATP competitive inhibitors of Aurora kinase (3LAU). The in vitro cytotoxicity investigation of the compounds on six human cancer cell lines (MCF-7, HL-60, SK-MEL-2, A549, OVCAR-3, and SW620) indicated that analogues 79a and 79c to be active on MCF-7 with $\mathrm{GI}_{50}$ values of 2.32 and $8.16 \mu \mathrm{g} / \mathrm{mL}$ respectively, whereas, 79b was active against lung cancer cell line A549 with $\mathrm{GI}_{50}$ value of $1.61 \mu \mathrm{g} / \mathrm{mL}$. Moreover, all the three active molecules were found to have potent anticancer activity against all the tested cell lines. Noteworthy, most of tested compounds showed selective doseresponse towards the breast, leukemia, and/or lung cancer cell lines. In SAR studies, the phenyl ring $\left(\mathrm{R}_{4}\right)$ was completely embedded in the hydrophobic domain. When the chain length in the azomethine part was increased by introducing isobutyl or cyclohexyl units, the hydrazono part moved more towards the activation loop having the AlaAsp-Phe. It was found that in all three classes, $R_{3}$ substitution was desirable for better interaction with hinge region and thereby increased binding energy than corresponding unsubstituted analogs. The docking studies on HAT derivatives with substituted phenyl rings at $\mathrm{R}_{4}$ revealed that in all classes -OMe substitutions increase binding affinity by reducing exposure penality affected through an orientation change in the active site. However, halogen substitutions were not much influential in modulating the binding affinity of the molecules in the 3LAU 
active site. Furthermore, modification of $\mathrm{R}_{4}$ with biologically relevant heterocyclic ring systems such as coumarin and indole led to enhanced binding energies wherein a more pronounced effect was found for indolyl derivatives. The in silico ADME prediction determined the drug-likeness of different molecules that follow up the rule of five (RO5). Based on ADME prediction results, the designed molecules theoretically exhibited good passive oral absorption (Fig. 16) [94].

In continuing of CDK2 inhibitors discovery, Vulpetti and coworkers were designed a new, selective, and potent CDK2 inhibitor compound $\mathbf{8 0}\left(\mathrm{IC}_{50}=20 \mathrm{nM}\right)$ by identifying a promising template, namely $\mathrm{N}$-(5-Bromo-1,3-thiazol2-yl)butanamide (original hit) through high throughput screening and combination of X-ray structure determination and structure-based drug design. The original hit inhibited CDK2/Cyclin A in an ATP-competitive manner with an $\mathrm{IC}_{50}$ of $808 \mathrm{nM}$. In docking model of original hit, residues Val18, Ala31, Val64, Leu134, Ala144 formed two hydrophobic surfaces that interacted with thiazole ring. A hydrogen bond was formed between the nitrogen of the thiazole ring and the amide nitrogen of Leu 83 and other hydrogen bond created between the amide- $\mathrm{NH}$ of compound 46 and carbonyl oxygen of Leu83. Presence of a hydrophobic pocket containing Phe80, Val18, Val64 and Ala144 interacted with the bromine atom. In compound 80, the aniline group located closely towards the hydrophobic residues Ile10. There were the key interactions between the sulfonamide moiety and Asp86 (the main and the side-chain atoms). A weak hydrogen-bond was formed with Lys89 that was solvent exposed. The presence of the isopropyl in position 5 and the para-sulfonamide aniline in position 2 have increased activity of compound $\mathbf{8 0}$ by two orders of magnitude with respect to the original hit. Moreover, the para sulfonamide aniline substituent brings about an improvement of both potency and selectivity (Fig. 16) [95].

The research group of Bestgen, have recognized aryl 2aminothiazoles $\mathbf{8 1}$ as a new class of CK2 (Ser/Thr protein kinase) inhibitors. The compounds binding in allosteric site outside the ATP pocket was confirmed by Enzyme kinetics, STD-NMR, circular dichroism spectroscopy, and native mass spectrometry. This new binding site was identified at the interface between the $\alpha \mathrm{C}$ helix and the flexible glycinerich loop through combination of the data and molecular docking studies. SAR studies revealed that the insertion of a carboxylic acid group turned out to be important that probably involve with ionic interactions in active site, as it could not be removed or replaced by the methyl ester. The lack of an aryl group at position 4 of the aminothiazole scaffold led to inactive analogue. Therefore, the aryl group plays a crucial role in inhibitory activity. Modulation of the electron density of this aromatic ring did not substantially change the inhibitory activity compared with that of the unsubstituted congener, while insertion of a bromosubstituent remarkably enhanced the affinity $\left(K_{i}=0.7 \mu \mathrm{M}\right)$ by increasing the lipophilicity. The most potent compound (82) obtained from the first hit optimization, showed a favorable selectivity profile with $\mathrm{IC}_{50}$ value of $3.4 \mu \mathrm{M}$ against purified CK2 $\alpha$. As a result, identification of a new class of CK2 inhibitors with targeting an allosteric site offer good potencies for further optimization into selective and drug-like leads (Fig. 16) [96].

Continuous efforts to identify allosteric modulators of the CK2 and following on previous work of Bestgen team, structure optimizations supported by a binding model led to the identification of the lead compound 2-hydroxy-4-((4(naphthalen-2-yl)thiazol-2-yl)amino)benzoic acid (83) from the 2-aminothiazolyl benzoic acid derivatives that showing $\mathrm{IC}_{50}$ value of $0.6 \mu \mathrm{M}$ against purified CK2 $\alpha$. The preliminary Structure-Activity Relationships had suggested that the three aryl ring system as well as the carboxylic acid function were needed for CK2 $\alpha$ inhibition and the $p$-position appeared most suitable for the placement of the essential acidic function. Although, the electron density of the phenyl ring in the thiazole 4-position was not relevant to the binding affinity. Compound $\mathbf{8 3}$ showed apoptosis induction and cell death in 786-O renal cell carcinoma cells with $\mathrm{EC}_{50}=5 \mu \mathrm{M}$ and suppressed activation of STAT3 more potently than CX-4945 $\left(\mathrm{EC}_{50}=1.6 \mu \mathrm{M}\right.$ and $\left.5.3 \mu \mathrm{M}\right)$. The high activity of analogue $\mathbf{8 3}$ in cells can be ascribed to the lack of binding competition with the high levels of intracellular ATP. The kinase selectivity profile exhibited that compound $\mathbf{8 3}$ was also about 40 times higher than that of CX-4945 (5-(3-chlorophenylamino)-benzo[c][2,6]naphthyridine-8-carboxylic acid, silmitasertib). The pharmacological profile of the 2-aminothiazolyl benzoic acid derivatives will be different from any ATP-competitive CK2 inhibitor, which was valuable for further investigation in in vivo models. As a hypothesis, phosphorylation of a typical regulatory element on the catalytic subunit does not modulate CK2 and it exists in a dynamic equilibrium between different conformations. Stimulating the phosphorylation was needed an additional interaction between FGF-2 and CK2 $\beta$ in the CK2-nucleolin complex. However, these novel ligands might be beneficial to research the conformational state of different CK2s in complexes with individual substrates, to illustrate the relevance of CK2 conformational stabilization for the modulation of its activity (Fig. 16) [97].

A new series of aminothiazole attachment on coumarin core as strong anticancer lead were identified with potential activity as energy restriction mimetic agents (ERMA). The recognized chemotypes could be inhibited glucose uptake and enhanced ROS generation in cancer cells. Derivatives 84a and 84b exhibited strong activity against HCT116 and HT-29. According to the structure-activity relationship, 
compound 84a was the most potent analogue with $\mathrm{IC}_{50}$ values of $0.38 \mu \mathrm{M}$ and $0.53 \mu \mathrm{M}$ against HT-29 and HCT116, and compound $\mathbf{8 4 b}$ was the safest analogue on normal cells with $\mathrm{IC}_{50}$ value of $7.97 \mu \mathrm{M}$. Further biological assessment of analogues 84a and 84b indicated that mediated glucose uptake inhibition, simplified ROS generation and decreased NADPH/NADP levels and finally induced cancer cell death through energy restriction, at least in part. Additionally, the evaluation of synergistic activity for $\mathbf{8 4 a}$ and $\mathbf{8 4 b}$ with cisplatin displayed promising results (Fig. 16) [98].

\section{Modification of 2-amine to 2-aminopyridine}

A new series of thiazole derivatives (3-((2-(pyridin-2-ylamino) thiazol-5-ylmethyl) _ amino) benzamides) were discovered by Borzilleri et al., as selective and potent VEGFR2 kinase inhibitors. Optimization of the discovered compounds led to the exploration of $\mathbf{8 5}$ (BMS-605541). In the SAR studies, insertion of a cyclopropyl substituent on amide group was well tolerated. In aqueous acidic conditions, presence of the fluorine in the position 4 of benzamide led to low chemical stability. In case of increasing the electron-deficiency of the benzamide ring, second fluorine was inserted. It was postulated that minimizing the potential of acid-catalyzed hydrolysis will occur in resulting decrease in basicity of the aniline nitrogen. Therefore, enhancing in solution stability at low $\mathrm{pH}$ was obtained. Compound $\mathbf{8 5}$ was an ATP-competitive inhibitor against VEGFR-2 kinase with $K_{\mathrm{i}}=49 \pm 9 \mathrm{nM}$ and $\mathrm{IC}_{50}=23 \mathrm{nM}$ and inhibited the hERG channel in HEK-293 cells with $\mathrm{IC}_{50}=16.6 \mu \mathrm{M}$. This analogue, in the human lung and colon carcinoma xenograft models showed orally activity at multiple dose levels. Also, compound 85 illustrated favorable pharmacokinetic profile; a moderate steady-state volume of distribution, low systemic clearance, favorable half-life and mean residence times and 100 and $52 \%$ oral bioavailabilities in mouse and monkey, respectively (Fig. 17) [99].

In a further work by Misra et al. were found N-Aryl aminothiazoles as potent CDK inhibitors (CDK1, CDK2, and CDK4). These compounds exhibited high potency on A2780 cells (in vitro). In determination of CDKs (CDK1, CDK2, CDK4) selectivity for synthesized compounds was identified that the nature of the $\mathrm{N}$-aryl group affected on selectivity. Indicating substituent para to the amino group on the aryl ring would be directed toward the exterior of the protein and thus should be compatible with maintaining CDK inhibitory activity. Compounds 86 (BMS-357075) indicated a pan-like CDK inhibitory activity. The amide backbone atoms of Leu83 created essential H-binding interaction with the thiazole nitrogen and exocyclic amine proton. Analysis indicated serum protein binding at $90 \%$ for $\mathbf{8 6}$. Analogue $\mathbf{8 6}$ with polar groups on the aryl ring displayed a potent inhibitor activity of $\mathrm{CDK} 1, \mathrm{CDK} 2$, and CDK4 with $\mathrm{IC}_{50}$ values 18,3 and $26 \mathrm{~nm}$, respectively and produced a $56 \%$ increase in survival time versus untreated control against P388 murine leukemia in mice (Fig. 17) [100].

Tomita et al. discovered a new derivatives of 1,7-disubstituted-6-fluoro-1,4-dihydro-4-oxo-1,8-naphthyridine-3carboxylic acids that have moderate cytotoxic effect. The SAR studies of these compounds performed by modifying positions of $\mathrm{N}-1$ and $\mathrm{C}-7$ and core ring in the structure. These synthesized compounds were assessed against different types of murine and human tumor cell lines (melanoma, stomach, colon, lung, ovary, and bladder). Based on the SAR studies, the 2-thiazolyl group was the optimal group at the N-1 position of the naphthyridine structure for improving antitumor activity. The aromatic groups were shown in order of decreasing activity: 2-thiazolyl $>2$ benzothiazolyl $>$ 3-methyl- 5-isoxazolyl $>$ 2-thienyl $>$ phenyl $=$ 4-fluorophenyl $>$ 1,3,4-thiadiazol-2-yl $>5$ isoxazolyl. 2-Pyridyl similar to 5-pyrazolyl didn't show activity. Different substituents affected on the thiazole ring in order of decreasing activity: unsubstituted $>4$-methyl $=$ 4-phenyl $>5$-bromo $=5$-chloro $>$ 4,5- dimethyl $>5$-methyl $>$ 5-methoxy $>$ 4-tertbutyl. According to the core, pyridopyrimidine analogue exhibited the most effect. Aminopyrrolidine group at the C-7 position was tolerable than others. In biological evaluation of derivatives, compounds 87a and 87b displayed good in vitro antitumor activity and in vivo assay (in mice bearing P388 leukemia) as well as AT-3639. The activity of these compounds can be compared with etoposide (Fig. 17) [101].

\section{Modification of 2-amine to 2-aminopyrimidine}

In order to find new entity of Src family kinase inhibitors containing 2-aminothiazole, Das et al. introduced a lead with weak biochemical potency on Lck and low cellular activity through their broad screening. Optimization through SAR iteractions distinguished analogues 5 (Dasatinib, BMS-354825) and $\mathbf{8 8}$ that were as very potent panSrc kinase inhibitors in biochemical and cellular assays. Compound 88 (2" $2^{\prime \prime} 6^{\prime \prime}$-di-Me-4"'-pyrimidinyl-substituted) exhibited Lck $K_{i}=130 \mathrm{pM}$, hLck $\mathrm{IC}_{50}=1 \mathrm{nM}$, T-cell $\mathrm{IC}_{50}=$ $80 \mathrm{nM}$ but Compound 5 was nearly 30-fold more potent than the lead on T-cells (hLck $\mathrm{IC}_{50}=0.4 \mathrm{nM}$ and T-cell $\mathrm{IC}_{50}=3 \mathrm{nM}$ ). Selectivity evaluation on a panel of in-house kinases was determined for compound $\mathbf{5}$ and $\mathbf{8 8}$. Compound $\mathbf{8 8}$ indicated a potential inhibitory on Src family kinases and Bcr-Abl kinase and showed highly selectivity on other tyrosine and serine/threonine kinases. Compound 5 significantly inhibited the Src family kinases and Bcr-Abl kinase with below nanomolar $\mathrm{IC}_{50}$ and also highly selective on other tested kinases. Using molecular modeling, a putative binding model was determined for Lck inhibition by synthesized compounds. The aniline $\mathrm{NH}$ created one 
Fig. 17 2-Aminothiazole scaffold containing pyridine moiety (85-87)<smiles>O=C(NC1CC1)c1cc(NCc2cnc(Nc3ccccn3)s2)c(F)cc1F</smiles>

85

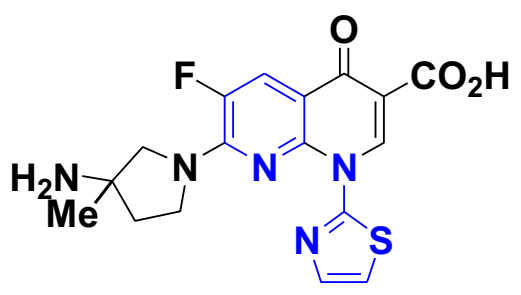

$87 a$

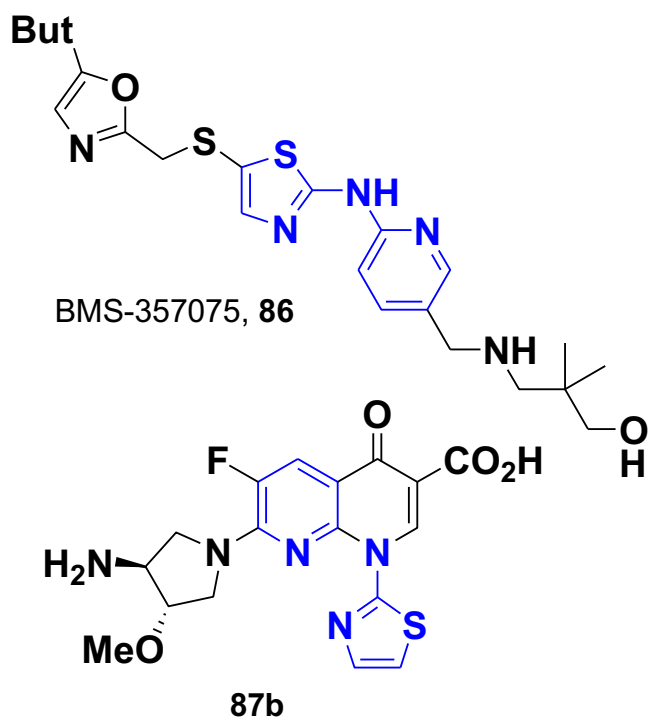

H-bond interaction with the Thr316 hydroxyl. Both thiazole nitrogen and amino group in 2-aminothiazole scaffold engaged in H-bond interaction with the $\mathrm{NH}$ and carbonyl of Met319. There was a relatively narrow hydrophobic pocket containing Leu251, Tyr318, and Gly322 that interacted with the 2-amino pyrimidine. The 4-hydroxyethylpiperazine residue in compound $\mathbf{5}$ did not engage in $\mathrm{H}$-bond interactions and approaches the solvent front. The oral efficacy of 88 was further determined in an adjuvant arthritis model in rats. The oral efficacy of these inhibitors was evaluated with compound $\mathbf{8 8}$ in inhibiting cytokine IL-2 ex vivo in mice and in reducing TNF levels in vivo in an acute murine model inflammation. Dasatinib (5) was used currently for the treatment of CML in clinical trials (Fig. 18) [102, 103].

Dasatinib is an orally active nonselective tyrosine kinase inhibitor, also inhibited tumor growth and angiogenesis by inhibiting PDGFR- $\beta$ and SFKs in tumor cells and tumorassociated endothelial cells. Encouraged by the successful development of dasatinib, several hydrophobic chains have been utilized in order to modification of Dasatinib and reported by Paunescu et al. Derivatives were assessed for their in vitro antiproliferative selectivity and in vivo antiangiogenic activity. Replacing of the hydroxyl group in dasatinib with alkyl and perfluoroalkyl chains led to a change in the selectivity profile by increasing the selectivity along with reducing in sensitivity of the drug. Increasing size of chain in derivatives showed significantly less inhibitory against A2780 cancer cells and a reasonable activity against ECRF24 cells. Moreover, these derivatives were inactive against human embryonic kidney cells (HEK-293) with $\mathrm{IC}_{50}$ $>500 \mu \mathrm{M}$. Derivative 89 with a long perfluorinated chain exhibited enhancement in angiostatic activity with the number of capillaries decreasing $45 \%$ that probably act through an antiproliferative mechanism (Fig. 18) [104].
Src family kinases (SFKs) are a family of non-receptor tyrosine kinases implicated in the regulation of many cellular processes. Considering the aberrant activity of these tyrosine kinases has been motivated Francini et al. to synthesis 2-aminothiazole analogues of dasatinib (5) and evaluation of their in vitro biological potential use as SFK inhibitors. For this purpose, linker between the 2aminothiazole moiety and the aromatic ring of dasatinib has been considered as a constraint in terms of exploring the distance between the hinge region and the hydrophobic pocket. They decided to substitute the amidic linker between the thiazole and the phenyl groups with alkyl chains (methyl or ethyl) or to remove it completely. Most of the tested compounds against the SFKs Src, Fyn, Lyn, and Yes were identified as the promising derivatives with $\mathrm{K}_{\mathrm{i}}$ values in the range of $90-480 \mathrm{nM}$. For compound 90 which the thiazole moiety is directly linked to the phenylring, $\mathrm{IC}_{50}$ value for the inhibition of $\mathrm{c}$-Src obtained $97 \mathrm{nM}$. This derivative also inhibited Yes, Lyn, and Fyn with $\mathrm{IC}_{50}$ range of 220-433 nM. In vitro assays, representative compound exhibited a significant antiproliferative activity on two cancer cell lines (SHSY5Y and K562). The modeling studies were used to find the possible and rational binding mode of designed compounds within the ATP binding site of the enzymes. These derivatives displayed an interaction pathway similar to dasatinib. Because of the absence of amide group in the thiazole family in compared with dasatinib, two H-bonds were found despite three $\mathrm{H}$-bonds in dasatinib. Compounds with a small and flexible $\mathrm{R}$ on the pyrimidine ring, could not stabilize their binding to the active site of c-Src enzyme. In both series of synthesized compounds, the best $\mathrm{R}$ group with good inhibitory profile was the (2-hydroxyethyl)-1-piperazinyl group that is present in dasatinib. Compound $\mathbf{9 0}$ caused a significant and 
<smiles>[R]c1cc(Nc2ncc(C(=O)Nc3c(C)cccc3Cl)s2)nc([R])n1</smiles>

5, $\mathrm{R}=4$-hydroxyethylpiperazine 88, $\mathrm{R}=\mathrm{CH}_{3}$

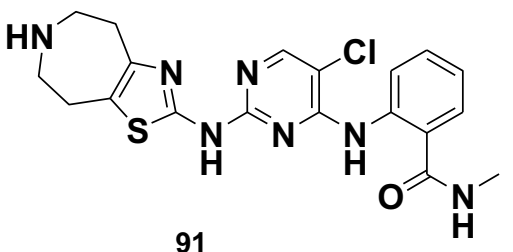<smiles>CCCCC(CCCCCCC(=O)OCCC(=O)OCCN1CCN(c2cc(Nc3nc(C)nc(Nc4ncc(-c5ccccc5)s4)n3)nc(C)n2)CC1)C(=O)Nc1ncc(C(=O)Nc2c(C)cccc2Cl)s1</smiles>

90

Fig. 18 2-Aminothiazole scaffold containing pyrimidine moiety

dose-dependent accumulation of both cell lines in the $\mathrm{G}_{1}$ phase (Fig. 18) [105].

Inspired by the pioneering work, Liu group developed a number of new 2,4-diarylaminopyrimidine derivatives incorporating a substituted 2-aminothiazole component as the C-2 substituent of the center pyrimidine core. They decided to conduct structural modifications based on original hit (91), which was maintained good potency against both ALK and c-Met with $\mathrm{IC}_{50}$ values of 61.8 and $20 \mathrm{nM}$, by replacing the $\mathrm{N}$-methylamide moiety on the C4-arylamino fragment of the central pyrimidine core with the isopropylsulfonyl group. Also, 1-methyl-N3-benzazepine and isopropylsulfonyl moieties were able to occupy the hydrophobic pocket of ALK kinase. These synthesized compounds showed different potencies on ALK kinase that compound 92 displayed the highest potency against ALK $\left(\mathrm{IC}_{50}=12.4 \mathrm{nM}\right)$ and ALK gatekeeper mutation L1196M $\left(\mathrm{IC}_{50}=24.1 \mathrm{nM}\right)$, whereas this selected compound exhibited moderate cellular potency against the SUP-M2 cells harboring NPM-ALK. Phosphorylation of ALK kinase and its down-stream signaling pathways were dose-dependently suppressed by compound 92. As a result, the 2aminothiazole scaffold as a heteroarylamino bioisosteric was suitable for replacement of the C2-phenylamino group in the pyrimidine core (Fig. 18) [106].

A benzamide HDAC inhibitor, MS-275 (93), is reported to be a selective HDAC inhibitor targeting class I HDACs, which is currently in phase II. Furthermore, reported X-ray crystal structure of Dasatinib (5) bound to Abl and MS-275 docked to HDAC1 homolog. The 2-aminothiazole of Dasatinib occupies the ATP-binding pocket of Abl with three hydrogen bonds. In the case of HDAC, 2aminophenylbenzamide moiety, which is one of the most potent zinc ion chelating group among all types of zincbinding groups and shows the potent selectivity to HADC1, forms four hydrogen bonds with His131, Asp168, Gly140, and His140. Given the known binding modes of the Abl inhibitor Dasatinib and HDAC1 inhibitor MS-275, it was envisaged that amalgamation of these pharmacophores would be a viable strategy to single molecules retaining both activities. Therefore, Chen et al. designed a new series of $\mathrm{N}$-(pyrimidin-4-yl)thiazol-2-amine derivatives with a novel design approach in the chimeric HDAC/kinase inhibitors. Among derivatives, compounds 94a and 94b exhibited the most active against HDAC1 and Bcr-Abl. Heterocycle group of $\mathrm{R}_{1}$ had a great impact on the effectiveness of the set of compounds against HDAC1. According to the SAR studies, presence of anilino or benzyl amino group in $\mathrm{R}_{1}$, replacement of the pyridyl group with a phenyl group in $R_{1}$ resulted in the decreased of enzymatic inhibitory activity against HDAC1. These results may suggest a preference for a certain hydrophilic group as a surface recognition cap group. Also, the fluorine substituent on the para-position of the amide had the similar effect. This result showed that this replacement of fluorine is helpless for the ZBG to chelate with the $\mathrm{Zn}^{2+}$ ion located at the bottom of the active site of HDAC1. The aromatic group in $R_{1}$ reduced Bcr-Abl inhibition and the fluorine atom on the para-position of the amide increased inhibitory activity against Bcr-Abl. Compound 94b exhibited the most potential inhibitory activity against $\mathrm{Bcr}-\mathrm{Abl}$ with an $\mathrm{IC}_{50}$ of $17.8 \mathrm{nM}$. In cellular assays, compound $\mathbf{9 4 a}$ and $\mathbf{9 4 b}$ as dual 

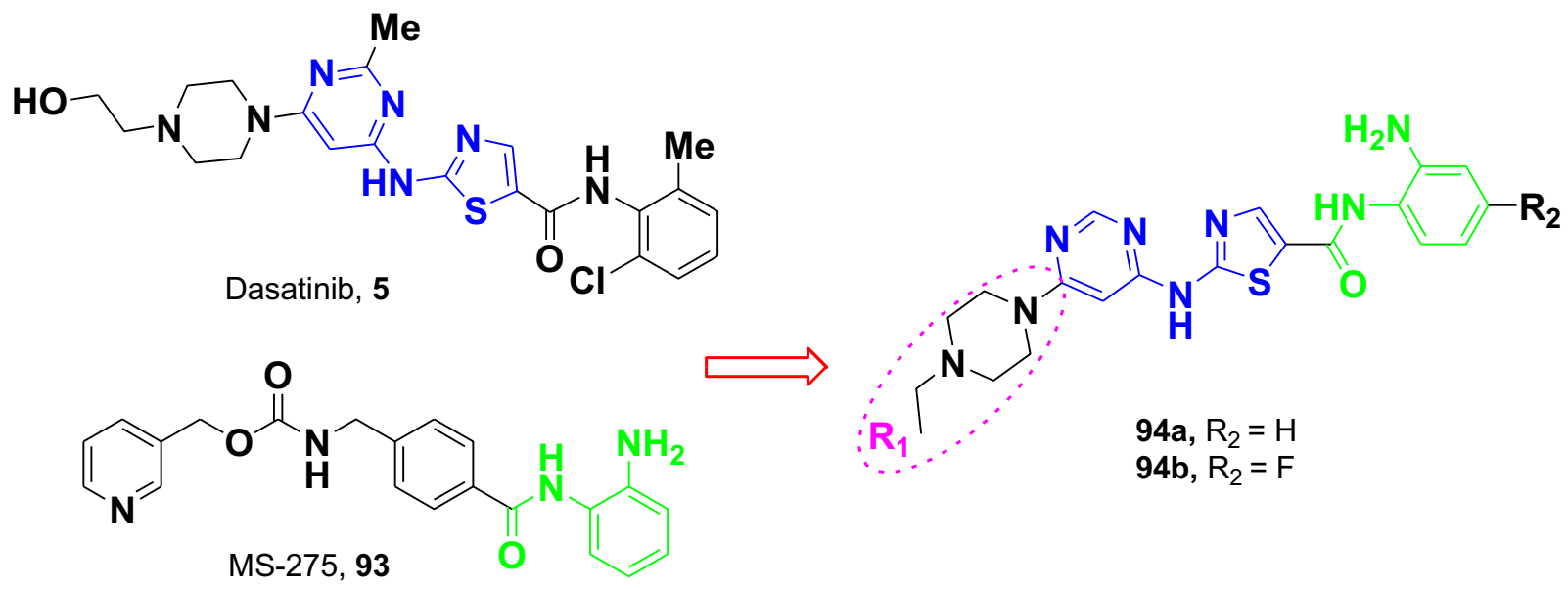

Fig. 19 Hybridization of dasatinib and MS-275 pharmacophores

Bcr-Abl/HDAC inhibitors displayed high antiproliferative activities against human leukemia cell line (K562) and prostate cancer cell line (DU145) (Fig. 19) [107].

\section{Modification of 2-amine to 2-schiff base}

Due to the presence of multifunctional groups in metal complexes of schiff bases with heterocyclic compounds, large numbers of schiff bases have also been shown to exhibit anticarcinogenic properties. The excessive attention of synthesizing determined broad range of $\mathrm{N}$ and $\mathrm{S}$ chelating ligands as thiazole molecule have enticed considerable interest. Besides these atoms play an important role in the coordination of metals at the active sites of diverse metal biomolecules that have a therapeutic activity or availing as study models for metallo-enzymes.

Following all these observations and as a part of AbdElzaher et al. continuing research on the coordination chemistry of multidentate ligands, compound (95) (E)-2(((5-methyl-4-phenylthiazol-2-yl)imino)methyl)phenol was prepared and formed novel complexes with cobalt, nickel, copper and zinc. These synthesized compounds were determined by different spectroscopic techniques; elemental analysis, magnetic susceptibility, molar conductance, infrared spectra, ${ }^{1} \mathrm{H}$ and ${ }^{13} \mathrm{C}$ NMR, mass, electronic absorption, and ESR spectroscopy. The new compounds were measured for their in vitro antiproliferative activity using the Sulfo-Rhodamine-B stain (SRB) assay against four human tumor cell lines; breast cancer MCF-7, liver cancer HepG2, lung carcinoma A549, and colorectal cancer HCT116. The reference drug in this study was doxorubicin. Among these compounds, Zn (II) complex indicated the most potent inhibitory against human TRK in HepG2, MCF7, A549, and HCT116 with inhibition percent of 80, 70,61 , and $64 \%$, respectively. The highest activity of the $\mathrm{Zn}$ (II) complex than the others may be attributed to the function of the $\mathrm{Zn}$ (II) complex as a competitive inhibitor of hemeoxygenase (HMOX1), which is produced in large amounts in solid tumors. The molecular modeling was performed for the investigation of the synthesized compounds as potential TRK inhibitors. The binding free energies of the prepared compounds into the target c-kit kinase receptor were calculated by MOE (molecular modeling environment). The best docking score obtained for $\mathrm{Zn}$ (II) and $\mathrm{Ni}(\mathrm{II})$, respectively (Fig. 20) [108].

In the same direction and in continuing effort to find more potent and selective anticancer schiff bases, anticancer activity of the prepared 4-tert-butyl-5-benzyl-2-benzyliminothiazoles derivatives from reacting the aromatic aldehydes with the corresponding 2-aminothiazoles by Jiao et al. was carried out against human cervix cancer (HeLa) cell line. Based on the antitumor bioassay, most of compounds with $p$-Cl substituent on the 5-benzyl fragment of the thiazole ring showed moderate to strong cytotoxic activities against HeLa cells. Among them, compounds 96a and 96b showed high potency with $\mathrm{IC}_{50}$ values of 0.001 and $0.007 \mathrm{mmol} / \mathrm{L}$, respectively, even higher than Cisplatin $\left(\mathrm{IC}_{50}=0.009 \mathrm{mmol} / \mathrm{L}\right)$. According to structure-activity relationship studies, displacement of electron-withdrawing $p$-chlorobenzyl with electron-donating $p$-methoxybenzyl on the thiazole significantly decreased the cytotoxic activities. For the para-chlorobenzyl series, substituent $\mathrm{X}$ and its position on the phenyl ring showed slight variations in their antitumor activities. Thiazoles with paraelectron-withdrawing $\left(4-\mathrm{Cl}, 4-\mathrm{NO}_{2}\right)$ on the phenyl ring are more active than a 4-electron-donating $\left[4-\mathrm{N}\left(\mathrm{CH}_{3}\right)_{2}\right]$ variant. Therefore, introducing electron-withdrawing substituent on the phenyl ring improves the potency of the compounds. Compound 96a was demonstrated a potential apoptosis inducer in HeLa cells, may be an efficient anticancer drug candidate (Fig. 20) [109].

Zhou and coworkers designed and prepared a number of new thiazolyl Schiff bases by combination of a novel series 
Fig. 20 Schiff base containing 2aminothiazole moiety<smiles>[X]c1ccc(/C=N/c2nc(C(C)(C)C)c(Cc3ccc(Cl)cc3)s2)cc1</smiles>

96a, $X=4-\mathrm{Cl}$

96b, $X=4-\mathrm{NO}_{2}$<smiles>Cc1sc(/N=C/c2ccccc2O)nc1-c1ccccc1</smiles>

of 2-aminothiazole with an arylidene moiety bearing different substituents. These compounds were evaluated for their antitumor activity against three different human tumor cell lines including HL-60; leukemia, BGC-823; stomach and HEP-2; larynx cancer by the MTT method and the SRB method. Among these compounds, compound $\mathbf{9 7}$ displayed acceptable antitumor activity and the highest inhibition percentage with 91.97, 98.49, and 91.16\% for HL-60, BGC823, and HEP-2, respectively. These selected compounds can be used for further in vitro assay against a wide panel of human cancer cell lines and the most active compounds were selected for preclinical in vivo studies (Fig. 20) [110].

A novel series of multi-heterocyclic Schiff base of imidazolylphenylheterocyclic-2-ylmethylenethiazole-2-amines were prepared and assessed for their in vitro cytotoxic activity against different human cancer cell lines including MCF7, HCT116, and DU145 and one normal skin fibroblast (SF). All derivatives exhibited $\mathrm{IC}_{50}$ values $<100 \mu \mathrm{mol} /$ L. Derivatives 98a-c indicated good activity against all cancerous cell lines. All synthesized compounds displayed $\mathrm{IC}_{50}$ values $>50 \mu \mathrm{mol} / \mathrm{L}$ against non-cancer normal skin fibroblast (SF) cells. According to the SAR studies, different features of substituents connected to the schiff base resulted in the interesting changes within pharmacological effects of molecular systems. The highest anticancer activity on MCF-7 cells was shown using a molecule with a benzothiazole $(\mathbf{9 8 b})$ connected to the azomethine $\left(\mathrm{IC}_{50}=\right.$ $27.76 \pm 2.14 \mu \mathrm{mol} / \mathrm{L}$ ). The existence of two heteroatoms such as $\mathrm{S}$ and $\mathrm{N}$ can be benefit to get an activity on MCF-7. Data recorded indicated that molecules with $\mathrm{S}$ heteroatom such as thiazole and thiophene played an excellent role against DU-145. The nitrogen-based heterocycles demonstrated significantly active on HCT116 (human colon cancer) cell line such as compounds with imidazole, pyrrole, and pyridine rings. As a result, the existence of special<smiles>O=[N+]([O-])c1ccc(/C=N/c2nc(-c3ccccc3)c(-n3cncn3)s2)c([N+](=O)[O-])c1</smiles>

97<smiles>[R]C=Nc1nc(-c2ccc(-n3ccnc3)cc2)cs1</smiles><smiles>O=Cc1nccs1</smiles>

$98 b, R=$<smiles>O=Cc1nc2ccccc2s1</smiles>

$98 c, R=$<smiles>O=Cc1ccc2ccccc2n1</smiles>

heteroatom and also existence of an additional benzene ring, showed a remarkable effect against MCF-7 and DU-145, and S-heterocycles were more active against these cell lines, whereas, N-heterocycles played an important role against HCT116 (Fig. 20) [111].

\section{Modification of 2-amine to 2-hydrazone}

In the study by Altintop et al. various thiazolyl hydrazone derivatives designed and synthesized. These derivatives evaluated for anticancer activity with targeting Akt on A549, C6 rat glioma, and NIH/3T3 cell lines. Compound 99 was the most potent and selective inhibitor than other derivatives against $\mathrm{A} 549$ and $\mathrm{C} 6$ cells with $\mathrm{IC}_{50}=12 \pm$ $1.73 \mu \mathrm{M}$ and $3.83 \pm 0.76 \mu \mathrm{M}$, respectively and Akt inhibitory percentage of compound $\mathbf{9 9}$ on C6 Cell line was $71.66 \pm 4.09 \%$ and on A549 Cell Line was $45.77 \pm 10.58 \%$. In addition, early and late apoptotic cell population (32.8\%) were increased in C6 cell line by compound $\mathbf{9 9}$ more than cisplatin $(28.8 \%)$ and notably inhibited the Akt enzyme. They studied the Akt active site and binding mode of compound 99 by performing molecular docking analysis. The phenyl ring of compound $\mathbf{9 9}$ formed $\pi-\pi$ stacking interaction and a direct hydrophobic interaction with phenyl ring in the Tyr272 residue of the active site of Akt. Based on Lipinski's rule of five, compound $\mathbf{9 9}$ was predicted as a potential orally bioavailable agent (Fig. 21) [112].

In another work, Altintop et al. was investigated some novel nitro-substituted thiazolyl hydrazone derivatives. In addition, in vitro evaluation of these compounds was performed on the MCF-7 and NIH/3T3 cell lines. Compound 100 was indicated inhibitory activity on MCF-7 with $\mathrm{IC}_{50}=125 \mu \mathrm{g} / \mathrm{mL}$ and comparatively low toxicity on NIH/ $3 \mathrm{~T} 3$ cells $\left(\mathrm{IC}_{50}\right.$ value $\left.>500 \mu \mathrm{g} / \mathrm{mL}\right)$. As a result, the presence of functional groups at the 5th position of the furan 


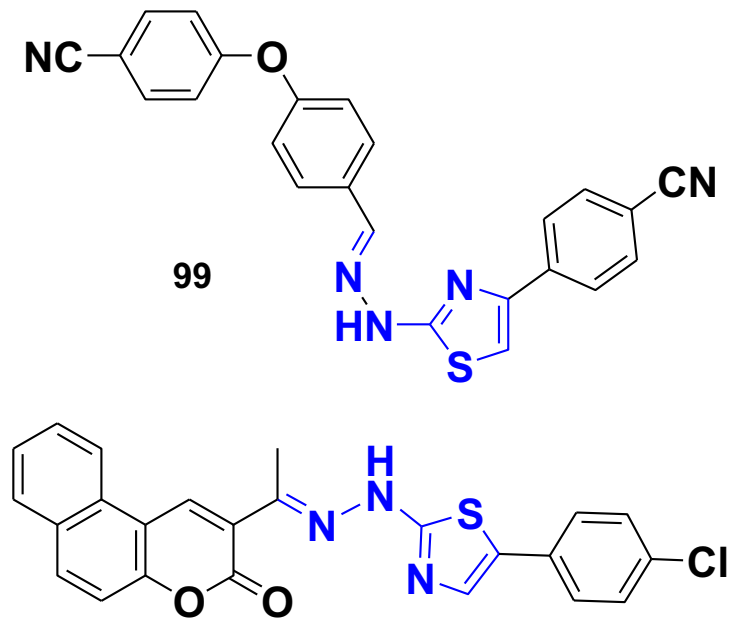

101<smiles>O=[N+]([O-])c1cc(Cl)ccc1-c1ccc(/C=N/Nc2nc(-c3ccc(Cl)cc3)cs2)o1</smiles>

100<smiles>[R]OCc1sc(NN=C(C)c2cc3cc([X])ccc3oc2=O)nc1C</smiles>

102a, $\mathrm{X}=\mathrm{Br}, \mathrm{R}=\mathrm{CH}_{3}$ 102b, $X=\mathrm{H}, \mathrm{R}=\mathrm{OCH}_{2} \mathrm{CH}_{3}$ 102c, $X=\mathrm{Cl}, \mathrm{R}=\mathrm{OCH}_{2} \mathrm{CH}_{3}$ 102d, $\mathrm{X}=\mathrm{Br}, \mathrm{R}=\mathrm{OCH}_{2} \mathrm{CH}_{3}$

Fig. 21 2-Aminothiazole scaffold containing hydrazone moiety (99-102)

ring and the 4th position of the thiazole ring probably was valuable on cytotoxicity against MCF-7 and NIH/3T3 cell lines. Among these derivatives, compound 100can be recognized as promising anticancer agent (Fig. 21) [113].

Mohamed et al. evaluated a novel synthesized derivative 101 on different human cell lines and Ehrlich ascites carcinoma (EAC) bearing mice. $\mathrm{IC}_{50}$ values for MCF-7, HepG2 and HCT-116 cell lines obtained $21.4 \pm 1.5(\mu \mathrm{g} /$ $\mathrm{mL}), 19.6 \pm 1.45(\mu \mathrm{g} / \mathrm{mL})$ and $20 \pm 2.1(\mu \mathrm{g} / \mathrm{mL})$, respectively. The major problem encountered in cancer chemotherapy is mainly because of iron deficiency finally leads to reduction in RBC count or hemoglobin content. Similarly, in this study RBCs count was increased in $\mathbf{1 0 1}$ by $51 \%$ compared to EAC control group that was reduced hemoglobin, RBC, and WBC count. Literature survey affirm that increase in life span of tumor-bearing mice, decrease in tumor volume and viable cell count and elevation of non-viable cell count is as a result of any antitumor agents efficacy. Also compound 101 significantly increases the life span of the EAC treated mice. Reported results proved the cytotoxic efficacy of $\mathbf{1 0 1}$ on tumor cells. Based on flow cytometric analysis, compound 101 increased P53 genes expression that induced Ehrlich cells apoptosis (Fig. 21) [114].

Motivated by the potential anticancer activity of both coumarin and 2-aminothiazole nucleus, a novel series of thiazol-2-yl hydrazono-chromen-2-one derivatives were synthesized by Abd El-Karim and coworkers. Potency of all the synthesized derivatives was investigated by MTT assay against HeLa cells. Among tested derivatives, most of them indicated more or equipotent cytotoxicity to doxorubicin, especially derivative 102a and derivatives $\mathbf{1 0 2 b}$-d with $\mathrm{IC}_{50}$ range of $0.0091-0.0654 \mu \mathrm{M}$ compared to doxorubicin with
$\mathrm{IC}_{50}$ value of $1.107 \mu \mathrm{M}$. According to cell cycle analysis, the compound 102b made cell cycle accumulation at G0/G1 phase by $62.19 \%$ compared with $37.23 \%$ by doxorubicin that showing CDK2/E1 complex could be considered the possible biological target for these novel derivatives. CDK2/E1 evaluation for the most promising derivatives (102a-d) exhibited remarkable inhibitory against the target enzyme with $\mathrm{IC}_{50}$ value ranging of $0.022-1.629 \mathrm{nM}$. RTPCR gene expression assay was proved that the levels of $\mathrm{P} 21$ and P27 as the nuclear CDK2 regulators increased using analogue 102b with 2.30 and 5.7 folds, respectively. Furthermore using, $\mathbf{1 0 2 b}$ significant activation of caspases3 and -9 induced cell apoptosis. Molecular docking analysis for 102a-d exhibited hydrogen bonding interactions with the main amino acids Leu83, Lys89, and Asp145 in the ATP binding site and hydrophobic interaction with the hydrophobic amino acids Ile10, Val18, Ala31, Val64, Phe80 and Gln85 that confirmed their significant CDK2 inhibitory activity. Pharmacokinetic properties prediction of the most potent compounds showed that the newly synthesized compounds are not only with promising antitumor activity but also possess promising pharmacokinetic properties (Fig. 21) [115].

\section{Miscellaneous}

The research group of Tsai in 2016, synthesized a new aminothiazole-paeonol derivatives and characterized by ${ }^{1} \mathrm{H}-$ NMR, ${ }^{13} \mathrm{C}-\mathrm{NMR}$, IR, mass spectroscopy, and HPLC. The substituents $\mathrm{F}, \mathrm{Cl}, \mathrm{Br}, \mathrm{NO}_{2}$, Me, and $\mathrm{OMe}$ were placed on the phenylsulfonyl. All derivatives were tested for their anticancer activity on fibroblast cells (BALB/3T3) and seven cancer cell lines (AGS, HeLa, PaTu8988t, HT-29, 
<smiles>[R]Oc1ccc(-c2csc(NS(=O)(=O)c3ccc([R6]([R16])([H])[H])cc3)n2)c(O)c1</smiles>

Fig. 22 2-Aminothiazole scaffold containing sulfonamide moiety for treating gastrointestinal adenocarcinoma

U87-MG, A549, and CT26.WT). According to the experimental results, these compounds demonstrated strong anticancer activity against human gastric adenocarcinoma (AGS cells) and human colorectal adenocarcinoma (HT-29 cells). Among these tested compounds, compound 103a exhibited the most inhibitory activity with $\mathrm{IC}_{50}$ values of $4.0 \mu \mathrm{M}, 4.4 \mu \mathrm{M}$ and $5.8 \mu \mathrm{M}$ for AGS, HT-29 cells, and HeLa cells, respectively. The second potent compound was compound 103b that indicated $\mathrm{IC}_{50}$ values of 7.2, 11.2 and $13.8 \mu \mathrm{M}$ to AGS, HT-29 and HeLa cells, respectively. These compounds were better than 5 -FU with $\mathrm{IC}_{50}$ values of 43.8 and $7.2 \mu \mathrm{M}$ against AGS and HT-29 and less cytotoxic against fibroblast cells (BALB/3T3) than 5-FU. Compound 103a had more water solubility than compound $103 \mathrm{~b}$. The replacement of flourine with methoxy group at the para position of the phenylsulfonyl moiety increased water solubility of the compound. The electron-donating $\mathrm{OCH}_{3}$ group in compound 103a increased hydrophilicity of structure and so increasing the water solubility. Introducing the $\mathrm{NO}_{2}$ group at the para-positions of the phenylsulfonyl terminal led to the most inactive compound (Fig. 22) [116].

\section{Conclusion}

Due to the importance of drug design and discovery in the field of anticancer chemotherapeutic agents, there is increasing attempts for finding new leads. Through the course of this project, several strategies are recognized for the structural refinement of 2-aminothiazole as well as modification of the attached group to 2-amino in 2aminothiazole framework; modification to amide, urea, alkylamine, arylamine, aminopyridine, aminopyrimidine, Schiff base, hydrazone, sulfonamide. Structure-activity studies of various substitutions of 2-aminothiazole are offered by the easy synthesis of this versatile pharmacophore. The expedition on 2-aminothiazole scaffold is highlighted with the recent entry of Dasatinib and Alpelisib to the clinic. This review accredit a new foundation for further lead optimization in the field of anticancer drug discovery and development.

Funding This research did not receive any specific grant from funding agencies in the public, commercial, or not-for-profit sectors.

\section{Compliance with ethical standards}

Conflict of interest The authors declare that they have no conflict of interest.

Publisher's note Springer Nature remains neutral with regard to jurisdictional claims in published maps and institutional affiliations.

\section{References}

1. WO Foye, TL Lemke, DA Williams, Principles of medicinal chemistry, Forth edn., PA: Williams and Wilkins, Media; 2002. p. 822 .

2. Stewart BW, Wild CP. World cancer report 2014. Lyon, France: International Agency for Research on Cancer (IARC); 2015.

3. Xie X, Yan Y, Zhu N, Liu G. Benzothiazoles exhibit broadspectrum antitumor activity: their potency, structure-activity and structure-metabolism relationships. Eur $\mathrm{J}$ Medicinal Chem. 2014;76:67-76.

4. Singh S, Hassan D, Aldawsari HM, Molugulu N, Kesharwani P. Immune checkpoint inhibitors: a promising anticancer therapy. Drug Discov Today. 2020;25:223-9.

5. Jin C, Liang YJ, He H, Fu L. Synthesis and antitumor activity of ureas containing pyrimidinyl group. Eur $\mathrm{J}$ Med Chem. 2011;46:429-32.

6. Dawane BS, Konda SG, Kamble VT, Chavan SA, Bhosale RB, Baseer MS. Multicomponent one-pot synthesis of substituted Hantzsch thiazole derivatives under solvent free conditions. E-J Chem. 2009;6:S358-62.

7. Ghaemmaghami S, May BCH, Renslo AR, Prusiner SB. Discovery of 2-aminothiazoles as potent antiprion compounds. J Virol. 2010;84:3408-12.

8. Arora P, Narang R, Bhatia S, Nayak SK, Singh SK, Narasimhan B. Synthesis, molecular docking and QSAR studies of 2, 4disubstituted thiazoles as antimicrobial agents. J Appl Pharm Sci. 2015;5:28-42.

9. Dobbelstein M, Moll U. Targeting tumour-supportive cellular machineries in anticancer drug development. Nat Rev Drug Discov. 2014;13:179-96.

10. Siddiqui N, Ahsan W. Synthesis, anticonvulsant and toxicity screening of thiazolyl-thiadiazole derivatives. Medicinal Chem Res. 2011;20:261-8.

11. Iino T, Tsukahara D, Kamata K, Sasaki K, Ohyama S, Hosaka H, et al. Discovery of potent and orally active 3-alkoxy-5-phenoxyN-thiazolyl benzamides as novel allosteric glucokinase activators. Bioorg Medicinal Chem. 2009;17:2733-43.

12. Gallardo-Godoy A, Gever J, Fife KL, Silber BM, Prusiner SB, Renslo AR. 2-aminothiazoles as therapeutic leads for prion diseases. J Medicinal Chem. 2011;54:1010-21.

13. Rios Martinez $\mathrm{CH}$, Durant-Archibold AA. Latest eesearch on synthetics compounds with antileishmanial activity. Mini-Rev Org Chem. 2018;15:330-42. 
14. Giri RS, Thaker HM, Giordano T, Williams J, Rogers D, Sudersanam V, et al. Design, synthesis and characterization of novel 2-(2,4disubstituted-thiazole-5-yl)-3-aryl-3H-quinazoline4-one derivatives as inhibitors of NF-kB and AP-1 mediated transcription activation and as potential anti-inflammatory agents. Eur J Medicinal Chem. 2009;44:2184-9.

15. Gorczynski MJ, Leal RM, Mooberry SL, Bushweller JH, Brown ML. Synthesis and evaluation of substituted 4-aryloxy- and 4-arylsulfanyl-phenyl-2-aminothiazoles as inhibitors of human breast cancer cell proliferation. Bioorg Medicinal Chem. 2004;12:1029-36.

16. Misra RN, Xiao H, Williams DK, Kim KS, Lu S, Keller KA, et al. Synthesis and biological activity of $\mathrm{N}$-aryl-2-aminothiazoles: potent pan inhibitors of cyclin-dependent kinases. Biorgan Medicinal Chem Lett. 2004;14:2973-7.

17. Kayagil I, Demirayak S. Synthesis and anticancer activities of some thiazole derivatives. Phosphorus, Sulfur Silicon Relat Elem. 2009;184:2197-207.

18. Juric D, Janku F, Rodón J, Burris HA, Mayer IA, Schuler M, et al. Alpelisib plus fulvestrant in PIK3CA-altered and PIK3CAwild-type estrogen receptor-positive advanced breast cancer. A phase 1b Clin trial. JAMA Oncol. 2019;5:e184475.

19. Conroy A, Stockett DE, Walker D, Arki MR, Hoch U, Fox JA, et al. SNS-032 is a potent and selective CDK 2, 7 and 9 inhibitor that drives target modulation in patient samples. Cancer Chemother Pharmacol. 2009;64:723-32.

20. Kim J, Moon SH, Kim BT, Chae CH, Lee JY, Kim SH, et al. A novel aminothiazole KY-05009 with potential to inhibit Traf2and Nck-Interacting Kinase (TNIK) attenuates TGF- $\beta 1$-mediated epithelial-to-mesenchymal transition in human lung adenocarcinoma A549 cells. PLoS ONE. 2014;9:e110180.

21. Jayanthan A, Ruan Y, Truong TH, Narendran A. Aurora kinases as druggable targets in pediatric leukemia: heterogeneity in target modulation activities and cytotoxicity by diverse novel therapeutic agents. PLoS ONE. 2014;9:e102741.

22. Saha SK, Gordan JD, Kleinstiver BP, Vu P, Najem MS, Yeo J, et al. Isocitrate dehydrogenase mutations confer dasatinib hypersensitivity and SRC dependence in intrahepatic cholangiocarcinoma. Cancer Discov. 2016;6:727-39.

23. Johnson FM, Agrawal S, Burris H, Rosen L, Dhillon N, Hong D, et al. Phase 1 pharmacokinetic and drug-interaction study of dasatinib in patients with advanced solid tumors. Cancer. 2010;116:1582-91.

24. Sharma PC, Bansal KK, Sharma A, Sharma D, Deep A. Thiazole-containing compounds as therapeutic targets for cancer therapy. Eur J Medicinal Chem. 2020;188:112016.

25. Garcia-Egido E, Wong SYF, Warrington BH, Hantzsch A. synthesis of 2-aminothiazoles performed in a heated microreactor system. Lab Chip. 2002;2:31-33.

26. Hantzsch A. Thiazoles from thiamides. Justus Liebigs Ann Chem. 1889;250:257-73.

27. Potewar TM, Ingale SA, Srinivasan KV. Efficient synthesis of 2,4-disubstituted thiazoles using ionic liquid under ambient conditions: a practical approach towards the synthesis of Fanetizole. Tetrahedron. 2007;63:11066-9.

28. Ghodse SM, Telvekar VN. Synthesis of 2-aminothiazole derivatives from easily available thiourea and alkyl/aryl ketones using aqueous $\mathrm{NaICl}_{2}$. Tetrahedron Lett. 2015;56:472-4.

29. Abedi-Jazini Z, Safari J, Zarnegar Z, Sadeghi M. A simple and efficient method for the synthesis of 2-Aminothiazoles under mild conditions. Polycycl Aromat Compd. 2016;38:231-5.

30. Schmitz VE, Striegler H. Aminothiazole aus Ketonen und Rhodanamin. J far praktiache Chem. 1970;312:359-65.

31. King LC, Rydb I. The reaction of Ketones with formamidine disulfide. J Am Chem Soc. 1947;69:1813-4.

32. Dziuk B, Kyzioł JB, Zaleski J, Ejsmont K, Zarychta B. Synthesis of 2-aminothiazole derivatives in easy two-step, one-pot reaction. J Heterocycl Chem. 2018;55:763-8.
33. Zhao R, Gove S, Sundeen JE, Chen BC. A new facile synthesis of 2-aminothiazole-5-carboxylates. Tetrahedron Lett. 2001;42:2101-2.

34. Astle MJ, Pierce JB. The preparation of 2-aminothiazole from cyclic acetals. J Org Chem. 1955;20:178-81.

35. Fan NJ, He QR, Duan M, Bai YB, Tang JJ. Synthesis and antiproliferative activity of D-ring substituted steroidal benzamidothiazoles. Steroids. 2016;112:103-8.

36. El-Messery SM, Hassan GS, Al-Omary FA, El-Subbagh HI. Substituted thiazoles VI. Synthesis and antitumor activity of new 2-acetamido-and 2 or 3-propanamido-thiazole analogs. Eur J Medicinal Chem. 2012;54:615-25.

37. Abou-Seri SM, Eldehna WM, Ali MM, El DAA. Ella, 1Piperazinylphthalazines as potential VEGFR-2 inhibitors and anticancer agents: synthesis and in vitro biological evaluation. Eur J Medicinal Chem. 2016;107:165-79.

38. Zhang ZH, Wu HM, Deng SN, Cai XY, Yao Y, Mwenda MC, et al. Design, synthesis, and anticancer activities of novel 2amino-4-phenylthiazole scaffold containing amide moieties. J Chem. 2018;2018:1-8.

39. Finiuk N, Hreniuh V, Ostapiuk YV, Matiychuk V, Frolov D, et al. Antineoplastic activity of novel thiazole derivatives. Biopolymers Cell. 2017;33:135-46.

40. Millet A, Plaisant M, Ronco C, Cerezo ML, Abbe P, Emilie J, et al. Discovery and optimization of $\mathrm{N}$-(4-(3-aminophenyl) thiazol-2-yl) acetamide as a novel scaffold active against sensitive and resistant cancer cells. $J$ Medicinal Chem. 2016;59:8276-92.

41. El-Subbagh HI, Abadi AH, Lehmann J. Synthesis and antitumor activity of ethyl 2-substituted-aminothiazole-4-carboxylate analogs. Arch der Pharmazie: Int J Pharm Medicinal Chem. 1999;332:137-42.

42. Zhu Y, Wei W, Ye T, Liu Z, Liu L, Luo Y, et al. Small molecule TH-39 potentially targets Hec1/Nek2 interaction and exhibits antitumor efficacy in K562 cells via G0/G1 cell cycle arrest and apoptosis induction. Cell Physiol Biochem. 2016;40:297-308.

43. Kim KS, Kimball SD, Misra RN, Rawlins DB, Hunt JT, Xiao H$\mathrm{Y}$, et al. Discovery of aminothiazole inhibitors of cyclindependent kinase 2: synthesis, $\mathrm{X}$-ray crystallographic analysis, and biological activities. J Medicinal Chem. 2002;45:3905-27.

44. Kim YH, Ha S, Kim J, Ham SW. Identification of KPNB1 as a cellular target of aminothiazole derivatives with anticancer activity. ChemMedChem. 2016;11:1406-9.

45. Kumar Y, Green R, Wise DS, Wotring LL, Townsend LB. Synthesis of 2, 4-disubstituted thiazoles and selenazoles as potential antifilarial and antitumor agents. 2. 2-Arylamido and 2alkylamido derivatives of 2-amino-4-(isothiocyanatomethyl) thiazole and 2-amino-4-(isothiocyanatomethyl) selenazole. J Medicinal Chem. 1993;36:3849-52.

46. Lee J, Kim SJ, Choi H, Kim YH, Lim IT, Yang H-M, et al. Identification of CKD-516: a potent tubulin polymerization inhibitor with marked antitumor activity against murine and human solid tumors. J Medicinal Chem. 2010;53:6337-54.

47. Li H, Wang X, Duan G, Xia C, Xiao Y, Li F, et al. Synthesis, antitumor activity and preliminary structure-activity relationship of 2-aminothiazole derivatives. Chem Res Chin Universities. 2016;32:929-37.

48. Liu W, Zhou J, Qi F, Bensdorf K, Li Z, Zhang H, et al. Synthesis and biological activities of 2-amino-thiazole-5-carboxylic acid phenylamide derivatives. Arch der Pharmazie. 2011;344:451-8.

49. Misra RN, Xiao HY, Kim KS, Lu S, Han WC, Barbosa SA, et al. $\mathrm{N}$-(cycloalkylamino) acyl-2-aminothiazole inhibitors of cyclindependent kinase 2. N-[5-[[[5-(1, 1-dimethylethyl)-2-oxazolyl] methyl] thio]-2-thiazolyl]-4-piperidinecarboxamide (BMS387032), a highly efficacious and selective antitumor agent. J Medicinal Chem. 2004;47:1719-28. 
50. Nofal ZM, Soliman EA, Abd El-Karim SS, El-Zahar MI, Srour AM, Sethumadhavan $S$, et al. Synthesis of some new benzimidazole-thiazole derivatives as anticancer agents. J Heterocycl Chem. 2014;51:1797-806.

51. Thanh Tung T, Thi Kim Oanh D, Thi Phuong Dung P, Van Hue TM, Ho S, et al. New benzothiazole/thiazole-containing hydroxamic acids as potent histone deacetylase inhibitors and antitumor agents. Medicinal Chem. 2013;9:1051-7.

52. Wu Z, Ding N, Tang Y, Ye J, Peng J, Hu A. Synthesis and antitumor activity of novel N-(5-benzyl-4-(tert-butyl) thiazol-2yl)-2-(piperazin-1-yl) acetamides. Res Chem Intermed. 2017;43:4833-50.

53. Zhang ZH, Wu HM, Deng SN, Chai RX, Mwenda MC, Peng Y-Y, et al. Synthesis and biological evaluation of 2, 4-disubstituted thiazole amide derivatives as anticancer agent. Chem Pap. 2019;73:355-64.

54. Lee YSE, Chuang SH, Huang LYL, Lai CL, Lin YH, Yang JY, et al. Discovery of 4-aryl-N-arylcarbonyl-2-aminothiazoles as Hec1/Nek2 inhibitors. Part I: optimization of in vitro potencies and pharmacokinetic properties. J Medicinal Chem. 2014;57:4098-110.

55. Schiedel M, Rumpf T, Karaman B, Lehotzky A, Oláh J, Gerhardt S, et al. Aminothiazoles as potent and selective Sirt2 inhibitors: a structure-activity relationship study. J Medicinal Chem. 2016;59:1599-612.

56. Al-Anazi KM, Mahmoud AH, AbulFarah M, Allam AA, Fouda $\mathrm{MM}$, Gaffer HE, et al. 2-Amino-5-arylazothiazole-based derivatives: in vitro cytotoxicity, antioxidant properties, and bleomycindependent DNA damage. ChemistrySelect. 2019;4:5570-6.

57. Ibrahim DA, Lasheen DS, Zaky MY, Ibrahim AW, Vullo D, Ceruso $M$, et al. Design and synthesis of benzothiazole-6sulfonamides acting as highly potent inhibitors of carbonic anhydrase isoforms I, II, IX and XII. Bioorg Medicinal Chem. 2015;23:4989-99.

58. Xie XX, Li H, Wang J, Mao S, Xin MH, Lu S-M, et al. Synthesis and anticancer effects evaluation of 1-alkyl-3-(6-(2-methoxy-3-sulfonylaminopyridin-5-yl) benzo [d] thiazol-2-yl) urea as anticancer agents with low toxicity. Bioorg Medicinal Chem. 2015;23:6477-85.

59. Schiavi B, Ahond A, Al-Mourabit A, Poupat C, Chiaroni A, Gaspard C, et al. Synthesis of 5-deazathiogirollines: analogs of a natural antitumor agent. Tetrahedron. 2002;58:4201-15.

60. Fairhurst RA, Gerspacher M, Imbach-Weese P, Mah R, Caravatti $\mathrm{G}$, Furet $\mathrm{P}$, et al. Identification and optimisation of 4, 5dihydrobenzo [1, 2-d: 3, 4-d] bisthiazole and 4, 5dihydrothiazolo $[4,5-\mathrm{h}]$ quinazoline series of selective phosphatidylinositol-3 kinase alpha inhibitors. Bioorg Medicinal Chem Lett. 2015;25:3575-81.

61. Li L, Zhang CL, Song HR, Tan CY, Ding HW, Jiang Y-Y, et al. Discovery of novel dual inhibitors of VEGFR and PI3K kinases containing 2-ureidothiazole scaffold. Chin Chem Lett. 2016;27:1-6.

62. Rostom SA, Faidallah HM, Radwan MF, Badr MH. Bifunctional ethyl 2-amino-4-methylthiazole-5-carboxylate derivatives: synthesis and in vitro biological evaluation as antimicrobial and anticancer agents. Eur J Medicinal Chem. 2014;76:170-81.

63. El-Subbagh H, Al-Obaid A. 2, 4-Disubstituted thiazoles II. A novel class of antitumor agents, synthesis and biological evaluation. Eur J Medicinal Chem. 1996;31:1017-21.

64. Bolchi C, Pallavicini M, Bernini SK, Chiodini G, Corsini A, Ferri N, et al. Thiazole- and imidazole-containing peptidomimetic inhibitors of protein Farnesyltransferase. Bioorg Medicinal Chem Lett. 2011;21:5408-12.

65. Straniero V, Pallavicini M, Chiodini G, Ruggeri P, Fumagalli L, Bolchi C, et al. Farnesyltransferase inhibitors: CAAX mimetics based on different biaryl scaffolds. Bioorg Medicinal Chem Lett. 2014;24:2924-7.
66. Sang CY, Tian HZ, Chen Y, Liu JF, Chen SW, Hui L. Synthesis and biological evaluation of $4 \beta$-(thiazol-2-yl) amino-4'-Odemethyl-4-deoxypodophyllotoxins as topoisomerase-II inhibitors. Bioorg Medicinal Chem Lett. 2018;28:71-6.

67. Qian X, Li Z, Yang Q. Highly efficient antitumor agents of heterocycles containing sulfur atom: linear and angular thiazonaphthalimides against human lung cancer cell in vitro. Bioorg Medicinal Chem. 2007;15:6846-51.

68. Lefranc F, Xu Z, Burth P, Mathieu V, Revelant G, Faria MVdC, et al. 4-Bromo-2-(piperidin-1-yl) thiazol-5-yl-phenyl methanone (12b) inhibits $\mathrm{Na}^{+} / \mathrm{K}^{+}$-ATPase and Ras oncogene activity in cancer cells. Eur J Medicinal Chem. 2013;63:213-23.

69. Walaa S, Mohamed NA, Weam S, Nossier ES, Mahmoud K. Synthesis, molecular modeling studies and biological evaluation of novel pyrazole derivatives as antitumor and EGFR inhibitors. Int J Pharm Technol. 2016;8:25192-209.

70. Ali AR, El-Bendary ER, Ghaly MA, Shehata IA. Novel acetamidothiazole derivatives: synthesis and in vitro anticancer evaluation. Eur J Medicinal Chem. 2013;69:908-19.

71. Balanean L, Braicu C, Berindan-Neagoe I, Nastasa C, Tiperciuc B, Verite P, et al. Synthesis of novel 2-metylamino-4-substituted1, 3-thiazoles with antiproliferative activity. Rev de ChimBuchar. 2014;65:1413-7.

72. Kumar R, Subban R, Sundaram K, Venkatachalapthi S, Ali M. Conventional and microwave assisted synthesis of 2aminothiazoles and oxazoles and their anti cancer activity. Indo Am J Pharm Res. 2015;5:555-61.

73. Gorczynski MJ, Leal RM, Mooberry SL, Bushweller JH, Brown ML. Synthesis and evaluation of substituted 4-aryloxy-and 4arylsulfanyl-phenyl-2-aminothiazoles as inhibitors of human breast cancer cell proliferation. Bioorg Medicinal Chem. 2004;12:1029-36.

74. Borková L, Frydrych I, Jakubcová N, Adámek R, Lišková B, Gurská S, et al. Synthesis and biological evaluation of triterpenoid thiazoles derived from betulonic acid, dihydrobetulonic acid, and ursonic acid. Eur J Medicinal Chem. 2020;185:111806

75. Hamed FI, Mohamed AA, Abouzied AS. The uses of 2-amino-4phenylthiazole in the synthesis of coumarin, pyran, pyridine and thiazole derivatives with antitumor activities. Open Access Libr J. 2017;4:1-14.

76. Prasanna D, Kavitha C, Raghava B, Vinaya K, Ranganatha S, Raghavan SC, et al. Synthesis and identification of a new class of (S)-2, 6-diamino-4, 5, 6, 7-tetrahydrobenzo [d] thiazole derivatives as potent antileukemic agents. Inv N. Drugs. 2010;28:454-65.

77. Romagnoli R, Baraldi PG, Brancale A, Ricci A, Hamel E, Bortolozzi R, et al. Convergent synthesis and biological evaluation of 2-amino-4-( $3^{\prime}, 4^{\prime}, 5^{\prime}$-trimethoxyphenyl)-5-aryl thiazoles as microtubule targeting agents. J Medicinal Chem. 2011;54:5144-53.

78. Romagnoli R, Baraldi PG, Salvador MK, Camacho ME, Preti D, Tabrizi MA, et al. Synthesis and biological evaluation of 2substituted-4-(3',4',5'-trimethoxyphenyl)-5-aryl thiazoles as anticancer agents. Bioorg Medicinal Chem. 2012;20:7083-94.

79. Ayati A, Esmaeili R, Moghimi S, Bakhshaiesh TO, Eslami-S Z, Majidzadeh-A K, et al. Synthesis and biological evaluation of 4amino-5-cinnamoylthiazoles as chalcone-like anticancer agents. Eur J Medicinal Chem. 2018;145:404-12.

80. Ayati A, Bakhshaiesh TO, Moghimi S, Esmaeili R, Majidzadeh-A $\mathrm{K}$, Safavi M, et al. Synthesis and biological evaluation of new coumarins bearing 2,4-diaminothiazole-5-carbonyl moiety. Eur J Medicinal Chem. 2018;155:483-91.

81. Ding C, Zhang Y, Chen H, Yang Z, Wild C, Chu L, et al. Novel nitrogen-enriched oridonin analogues with thiazole-fused A-ring: protecting group-free synthesis, enhanced anticancer profile, 
and improved aqueous solubility. J Medicinal Chem. 2013;56:5048-58.

82. Vogt D, Weber J, Ihlefeld K, Brüggerhoff A, Proschak E, Stark H. Design, synthesis and evaluation of 2-aminothiazole derivatives as sphingosine kinase inhibitors. Bioorg Medicinal Chem. 2014;22:5354-67.

83. Yamada T, Shitashige M, Yokota K, Sawa M, Moriyama H, TNIK Inhibitor and the use. (2010). date: 03.06.2010 Patent application number: US20100137386A1.

84. Wan L, Jiao Y, Fang S, Junmei P, Aixi H. Synthesis, crystal structure and antitumor activity of 4-tert-Butyl-N-(2-fluorophenyl)-5-(1H-1, 2, 4-triazol-1-yl)-thiazol-2-amine. Steractural Chem. 2012;31:1782-6.

85. Gustin DJ, Li Y, Brown ML, Min X, Schmitt MJ, Wanska W, et al. Structure guided design of a series of sphingosine kinase (SphK) inhibitors. Bioorg Medicinal Chem Lett. 2013;23:4608-16.

86. Rex K, Jeffries S, Brown ML, Carlson T, Coxon A, Fajardo F, et al. Sphingosine kinase activity is not required for tumor cell viability. PLoS ONE. 2013;8:e68328

87. Aurelio L, Scullino CV, Pitman MR, Sexton A, Oliver V, Davies L, et al. From sphingosine kinase to dihydroceramide desaturase: a structure-activity relationship (SAR) study of the enzyme inhibitory and anticancer activity of 4-(4-(4-chlorophenyl) thiazol-2-yl) amino) phenol (SKI-II). J Medicinal Chem. 2016;59:965-84.

88. French KJ, Schrecengost RS, Lee BD, Zhuang Y, Smith SN, Eberly JL, et al. Discovery and evaluation of inhibitors of human sphingosine kinase. Cancer Res. 2003;63:5962-69.

89. Kayagil I, Demirayak S. Synthesis and anticancer activities of some thiazole derivatives. Phosphorus, Sulfur, Silicon. 2009;184:2197-207.

90. Schonbrunn E, Betzi S, Alam R, Martin MP, Becker A, Han H, et al. Development of highly potent and selective diaminothiazole inhibitors of cyclin-dependent kinases. J Medicinal Chem. 2013;56:3768-82.

91. Shi HB, Zhang SJ, Ge QF, Guo DW, Cai CM, Hu W-X, et al. Synthesis and anticancer evaluation of thiazolyl-chalcones. Bioorg Medicinal Chem Lett. 2010;20:6555-9.

92. Stieber F, Mazitschek R, Soric N, Giannis A, Waldmann H. Traceless solid-phase synthesis of 2-aminothiazoles: receptor tyrosine kinase inhibitors with dual selectivity for Tie-2 and VEGFR-2. Angew Chem Int Ed. 2002;41:4757-61.

93. Sun M, Xu Q, Xu J, Wu Y, Wang Y, Zuo D, et al. Synthesis and bioevaluation of $\mathrm{N}$, 4-diaryl-1, 3-thiazole-2-amines as tubulin inhibitors with potent antiproliferative activity. PloS ONE. 2017; 12:e0174006

94. Titus S, Sreejalekshmi KG. Enriching biologically relevant chemical space around 2-aminothiazole template for anticancer drug development. Medicinal Chem Res. 2018;27:23-36.

95. Vulpetti A, Casale E, Roletto F, Amici R, Villa M, Pevarello P, et al. Structure-based drug design to the discovery of new 2-aminothiazole CDK2 inhibitors. J Mol Graph Model. 2006;24:341-8.

96. Bestgen B, Krimm I, Kufareva I, Kamal AAM, Seetoh WG, Abell C, et al. 2-Aminothiazole derivatives as selective allosteric modulators of the protein kinase CK2. 1. identification of an allosteric binding site. J Medicinal Chem. 2019;62:1803-16.

97. Bestgen B, Kufareva I, Seetoh W, Abell C, Hartmann RW, Abagyan R, et al. 2-Aminothiazole derivatives as selective allosteric modulators of the protein kinase CK2. 2. structurebased optimization and investigation of effects specific to the allosteric mode of action. J Medicinal Chem. 2019;62:1817-36.

98. Hersi F, Omar HA, Al-Qawasmeh RA, Ahmad Z, Jaber AM, Zaher DM, et al. Design and synthesis of new energy restriction mimetic agents: potent anti-tumor activities of hybrid motifs of aminothiazoles and coumarins. Sci Rep. 2020;10:1-17.

99. Borzilleri RM, Bhide RS, Barrish JC, D'Arienzo CJ, Derbin GM, Fargnoli J, et al. Discovery and evaluation of N-cyclopropyl-2, 4-difluoro-5-((2-(pyridin-2-ylamino) thiazol-5-ylmethyl) amino) benzamide (BMS-605541), a selective and orally efficacious inhibitor of vascular endothelial growth factor receptor-2. J Medicinal Chem. 2006;49:3766-9.

100. Misra RN, Xiao HY, Williams DK, Kim KS, Lu S, Keller KA, et al. Synthesis and biological activity of $\mathrm{N}$-aryl-2-aminothiazoles: potent pan inhibitors of cyclin-dependent kinases. Bioorg Medicinal Chem Lett. 2004;14:2973-7.

101. Tomita K, Tsuzuki Y, Shibamori KI, Tashima M, Kajikawa F, Sato Y, et al. Synthesis and structure-activity relationships of novel 7-substituted 1, 4-dihydro-4-oxo-1-(2-thiazolyl)-1, 8naphthyridine-3-carboxylic acids as antitumor agents. Part 1. J Medicinal Chem. 2002;45:5564-75.

102. Das J, Chen P, Norris D, Padmanabha R, Lin J, Moquin RV, et al. 2-Aminothiazole as a novel kinase inhibitor template. Structure-activity relationship studies toward thediscovery of $\mathrm{N}$ (2-chloro-6-methylphenyl)-2-[[6-[4-(2-hydroxyethyl)-1-piperazinyl)]-2-methyl-4-pyrimidinyl] amino)]-1, 3-thiazole-5carboxamide (dasatinib, BMS-354825) as a potent pan-Src kinase inhibitor. J Medicianl Chem. 2006;49:6819-32.

103. Lombardo LJ, Lee FY, Chen P, Norris D, Barrish JC, Behnia K, et al. Discovery of N-(2-chloro-6-methyl-phenyl)-2-(6-(4-(2hydroxyethyl)-piperazin-1-yl)-2-methylpyrimidin-4-ylamino) thiazole-5-carboxamide (BMS-354825), a dual Src/Abl kinase inhibitor with potent antitumor activity in preclinical assays. J Medicinal Chem. 2004;47:6658-61.

104. Păunescu E, Clavel CM, Nowak-Sliwinska P, Griffioen AW, Dyson PJ. Improved angiostatic activity of dasatinib by modulation with hydrophobic chains. ACS Medicinal Chem Lett. 2015;6:313-7.

105. Francini CM, Fallacara AL, Artusi R, Mennuni L, Calgani A, Angelucci A, et al. Identification of aminoimidazole and aminothiazole derivatives as Src family kinase inhibitors. ChemMedChem. 2015;10:2027-41.

106. Liu Z, Yue X, Song Z, Peng X, Guo J, Ji Y, et al. Design, synthesis and pharmacological evaluation of 2-(thiazol-2-amino)-4-arylaminopyrimidines as potent anaplastic lymphoma kinase (ALK) inhibitors. Eur J Medicinal Chem. 2014;86:438-48.

107. Chen X, Zhao S, Wu Y, Chen Y, Lu T, Zhu Y, et al. Design, synthesis and biological evaluation of 2-amino-N-(2-aminophenyl) thiazole-5-carboxamide derivatives as novel Bcr-Abl and histone deacetylase dual inhibitors. RSC Adv. 2016;6:103178-84.

108. Abd-Elzaher MM, Labib AA, Mousa HA, Moustafa SA, Ali MM, El-Rashedy AA, et al. Synthesis, anticancer activity and molecular docking study of Schiff base complexes containing thiazole moiety. Beni-Suef Univ J Basic Appl Sci. 2016:5:85-96.

109. Ye J, Qiu S, Hu A, Peng J, Qin Z. Synthesis and antitumor activity of 4-tert-butyl-5-benzyl-2-benzyliminothiazoles. Chem Res Chin Universities. 2014;30:49-54.

110. Zhou X, Shao L, Jin Z, Liu JB, Dai H, Fang JX, et al. Synthesis and antitumor activity evaluation of some schiff bases derived from 2-aminothiazole derivatives. Heteroat Chem: Int J Main Group Elem. 2007;18:55-59.

111. Parekh NM, Mistry BM, Pandurangan M, Shinde SK, Patel RV. Investigation of anticancer potencies of newly generated Schiff base imidazolylphenylheterocyclic-2-ylmethylenethiazole-2amines. Chin Chem Lett. 2017;28:602-6.

112. Altıntop MD, Sever B, Akalın Çiftçi G, Özdemir A. Design, synthesis, and evaluation of a new series of thiazole-based anticancer agents as potent Akt inhibitors. Molecules. 2018;23:1318.

113. Altıntop MD, Özdemir A, Turan-Zitouni G, Ilgın S, Atlı Ö, Demirci $F$, et al. Synthesis and in vitro evaluation of new nitrosubstituted thiazolyl hydrazone derivatives as anticandidal and anticancer agents. Molecules. 2014;19:14809-20. 
114. Mohamed FZ, Abdelhamid MS, Elbaz HA. Biochemical studies of (5-P-chlorophenyl -2-benzo 5, 6-coumarin-3-yelthylidene aminothiazole) as antitumor agent. Asian J Res Biochem. 2018;3:1-16.

115. El-Karim SSA, Syam YM, El Kerdawy AM, Abdelghany TM. New thiazol-hydrazono-coumarin hybrids targeting human cervical cancer cells: synthesis, CDK2 inhibition, QSAR and molecular docking studies. Bioorg Chem. 2019;86:80-96.

116. Tsai CY, Kapoor M, Huang YP, Lin HH, Liang YC, Lin Y-L, et al. Synthesis and evaluation of aminothiazole-paeonol derivatives as potential anticancer agents. Molecules. 2016;21:145 